\title{
Diversity and toxigenicity of fungi and description of Fusarium madaense sp. nov. from cereals, legumes and soils in north-central Nigeria
}

Chibundu N. Ezekiel ${ }^{1,2}$, Bart Kraak ${ }^{3}$, Marcelo Sandoval-Denis ${ }^{3}$, Michael Sulyok², Oluwawapelumi A. Oyedele', Kolawole I. Ayeni', Oluwadamilola M. Makinde', Oluwatosin M. Akinyemi', Rudolf Krska, ${ }^{2,4}$, Pedro W. Crous ${ }^{3}$, Jos Houbraken ${ }^{3}$

I Department of Microbiology, Babcock University, Ilishan Remo, Ogun State, Nigeria 2 Institute of Bioanalytics and Agro-Metabolomics, Department of Agrobiotechnology (IFA-Tulln), University of Natural Resources and Life Sciences Vienna (BOKU), Konrad Lorenzstr. 20, A-3430 Tulln, Austria 3 Westerdijk Fungal Biodiversity Institute, Uppsalalaan 8, 3584 CT Utrecht, The Netherlands 4 Institute for Global Food Security, School of Biological Sciences, Queen's University Belfast, University Road, Belfast, BT7 1NN, Northern Ireland, UK

Corresponding author: Chibundu N. Ezekiel (chaugez@gmail.com)

Academic editor: C. Gueidan | Received 31 March 2020 | Accepted 15 April 2020 | Published 8 June 2020

Citation: Ezekiel CN, Kraak B, Sandoval-Denis M, Sulyok M, Oyedele OA, Ayeni KI, Makinde OM, Akinyemi OM, Krska R, Crous PW, Houbraken J (2020) Diversity and toxigenicity of fungi and description of Fusarium madaense sp. nov. from cereals, legumes and soils in north-central Nigeria. MycoKeys 67: 95-124. https://doi.org/10.3897/ mycokeys.67.52716

\begin{abstract}
Mycological investigation of various foods (mainly cowpea, groundnut, maize, rice, sorghum) and agricultural soils from two states in north-central Nigeria (Nasarawa and Niger), was conducted in order to understand the role of filamentous fungi in food contamination and public health. A total of 839 fungal isolates were recovered from $84 \%$ of the 250 food and all 30 soil samples. Preliminary identifications were made, based on macro- and micromorphological characters. Representative strains ( $\mathrm{n}=121)$ were studied in detail using morphology and DNA sequencing, involving genera/species-specific markers, while extrolite profiles using LC-MS/MS were obtained for a selection of strains. The representative strains grouped in seven genera (Aspergillus, Fusarium, Macrophomina, Meyerozyma, Neocosmospora, Neotestudina
\end{abstract}

Copyright C.N. Ezekiel et al. This is an open access article distributed under the terms of the Creative Commons Attribution License (CC BY 4.0), which permits unrestricted use, distribution, and reproduction in any medium, provided the original author and source are credited. 
and Phoma). Amongst the 21 species that were isolated during this study was one novel species belonging to the Fusarium fujikuroi species complex, F. madaense sp. nov., obtained from groundnut and sorghum in Nasarawa state. The examined strains produced diverse extrolites, including several uncommon compounds: averantinmethylether in A. aflatoxiformans; aspergillimide in A. flavus; heptelidic acid in A. austwickii; desoxypaxillin, kotanin A and paspalitrems (A and B) in A. aflatoxiformans, A. austwickii and $A$. cerealis; aurasperon $\mathrm{C}$, dimethylsulochrin, fellutanine $\mathrm{A}$, methylorsellinic acid, nigragillin and pyrophen in A. brunneoviolaceus; cyclosporins (A, B, C and $\mathrm{H}$ ) in A. niger; methylorsellinic acid, pyrophen and secalonic acid in $A$. piperis; aspulvinone $\mathrm{E}$, fonsecin, kojic acid, kotanin A, malformin $\mathrm{C}$, pyranonigrin and pyrophen in A. vadensis; and all compounds in F. madaense sp. nov., Meyerozyma, Neocosmospora and Neotestudina. This study provides snapshot data for prediction of food contamination and fungal biodiversity exploitation.

\section{Keywords}

Aflatoxins, chemotaxonomy, food safety, Fusarium, mycology, secondary metabolites

\section{Introduction}

Fungi are ubiquitous and diverse, inhabiting various environments including agricultural soils and the crops grown on them (Stajich et al. 2009). Fungi in soil can contaminate, invade and colonise crops on the field during pre-harvest stages and can remain present during the post-harvest processing stages. Depending on the processing steps, these fungi may later spoil foods during storage or in households or markets when storage conditions are sub-optimal and climatic conditions are favourable for their growth (Prange et al. 2005, Taniwaki et al. 2018). Thus, fungal contamination and colonisation of crops could directly lead to pre- and post-harvest food losses, mycotoxin contamination and indirectly to public health risks from consumption of mycotoxincontaminated foods (Avery et al. 2019). Additionally, soil could serve as a reservoir for pathogenic fungi, constituting public health hazards to farmers who spend much of their time on farms and have direct contact with agricultural soils. On the positive side, beneficial fungi, including biological control strains and species of industrial relevance, are also present in agricultural soils, waiting to be explored (Donner et al. 2009, Bautista-Rosales et al. 2013, Bandyopadhyay et al. 2016).

Proper characterisation of fungi is fundamental to effectively determine their ecology and roles in the environment. In Nigeria, several studies have focused on fungal contamination of food crops (Adebajo et al. 1994, Bankole et al. 2003, Marley et al. 2004, Afolabi et al. 2006, Adejumo et al. 2007, Atehnkeng et al. 2008, Makun et al. 2009, 2011, Fapohunda et al. 2012, Abdus-Salaam et al. 2016, Oyedele et al. 2017, Ezekiel et al. 2013a, 2013b, 2014, 2016, 2019, Frisvad et al. 2019, Akinfala et al. 2020) and soil (Donner et al. 2009, Bandyopadhyay et al. 2019, Ezekiel et al. 2019). Many of these reports focused mainly on characterising aflatoxigenic Aspergillus species, because of their high incidence and their ability to produce aflatoxins and less on other mycotoxins produced by other fungal genera and species. Thus, studies on characterisation of other fungi including Fusarium, a genus also comprising im- 
portant mycotoxin producers, have rarely been conducted in Nigeria (Marley et al. 2004, Afolabi et al. 2006, Adejumo et al. 2007, Makun et al. 2011, Fapohunda et al. 2012). Regardless of the fungal genera studied, the application of robust taxonomic tools comprising a combination of phenotypic characterisation, DNA sequence-based methods and extrolite profiling for fungal identification is scarce (Frisvad et al. 2019, Ezekiel et al. 2020, Akinfala et al. 2020). This comprehensive approach is valuable due to the high precision, based on the use of species-specific DNA markers (Houbraken et al. 2011, 2012, Samson et al. 2014, 2019).

Therefore, in view of the need to understand the roles of fungi in food contamination and other processes, we conducted a mycological investigation into agricultural crops (foods) commonly consumed and available in agrarian households and soils on which the crops were grown in two north-central states (Nasarawa and Niger) in Nigeria. The two states were selected for this study, based on previous reports (Adetunji et al. 2014, Abdus-Salaam et al. 2015, Oyedele et al. 2017) that implicated these states and/or the agro-ecological zone to which they belong (Southern Guinea Savanna) as regions of moderate-to-high aflatoxin and fumonisin contamination in foods. Consequently, it was necessary to study the fungal diversity in these states.

\section{Materials and methods}

\section{Food and soil sampling}

Various food $(\mathrm{n}=250)$ and soil $(\mathrm{n}=30)$ samples were collected in two states (Nasarawa and Niger) in north-central Nigeria. Samples were collected in September 2018 (harvest season) and January 2019 (storage season). The distribution of samples by sampling season were: harvest (food, $\mathrm{n}=143$ ) and storage (food, $\mathrm{n}=107$; soil, $\mathrm{n}=30$ ). Samples were collected from households within one week of harvest and after three months of storage (storage samples). In each state, food samples (1 kg per sample) were collected from households within three randomly selected communities that are at least 5-20 km apart: Mada station, Tundun Adabu and Yelwa Doma in Nasarawa state and Diko, Nubwa Koro and Sabon Wuse in Niger state. The food samples collected included: cowpea $(n=7)$; groundnut $(n=53)$, maize $(n=142)$, millet $(n=1)$, rice $(n$ $=23$ ) and sorghum $(n=24)$. Soil samples were collected from the farmlands belonging to five randomly selected households in each community. Sampled fields were at least $1 \mathrm{~km}$ apart. In each field, one composite sample (90-100 g) was collected by traversing the field and taking five subsamples from random points. The depth of soil sampling was 3-4 cm.

Food samples were placed in polyethylene bags whilst soil samples were placed in paper bags. All food samples were fragmented in an electric blender (MX-AC400, Panasonic, India) and stored at $4^{\circ} \mathrm{C}$ prior to analysis within $48 \mathrm{~h}$. Soil samples were transferred to plastic bags and clods were crushed using a mortar and pestle. Soil samples were then homogenised by hand-mixing prior to immediate fungal analysis. 


\section{Mycological studies of food and soil}

\section{Fungal isolation}

Filamentous fungi, present in the food and soil samples, were isolated and enumerated using the dilution plating technique described by Samson et al. (1995). The fragmented samples $(10 \mathrm{~g}$ each $)$ were diluted in sterile distilled water $(90 \mathrm{ml})$. Each mixture was homogenised on a vortex mixer for 2 min prior to surface-plating of $100 \mu \mathrm{l}$ on malt extract agar (MEA; Oxoid, UK). The inoculated plates were incubated at $25^{\circ} \mathrm{C}$ for 3 to $5 \mathrm{~d}$. The number of fungal colonies on the plates was counted and the colony forming units per gram (CFU/g) of the analysed samples calculated. Distinct colonies, appearing on the isolation plates, were carefully transferred to freshly prepared MEA plates and incubated at $25^{\circ} \mathrm{C}$ for $7 \mathrm{~d}$. All pure cultures were stored at $25^{\circ} \mathrm{C}$ on MEA slants in $4 \mathrm{ml}$ vials covered with sterile distilled water.

\section{Characterisation of fungal isolates}

Fungal isolates from the food and soil samples were characterised, based on morphological characteristics, DNA sequence data and/or secondary metabolites. The strains were first cultivated on MEA and assessed for macro- and microscopic characters, which were then compared with descriptions in appropriate keys (Frisvad and Samson 2004, Leslie and Summerell 2006, Pitt and Hocking 2009, Samson et al. 2011, 2019). Phenotypically similar isolates were grouped and selected isolates representing each group were identified using a sequence-based approach. For Fusarium and Neocosmospora spp., colony features and growth rates were assessed using MEA, oatmeal agar (OA), potato dextrose agar (PDA; recipes in Crous et al. 2019) and synthetic nutrientpoor agar (SNA; Nirenberg 1976); and micromorphology was studied using carnation leaf agar (CLA; Fisher et al. 1982) and SNA following protocols described elsewhere (Leslie and Summerell 2006, Sandoval-Denis et al. 2018). For the molecular analysis, DNA was extracted from each selected isolate previously cultivated on MEA at $25^{\circ} \mathrm{C}$ for $5 \mathrm{~d}$. Parts of the $\beta$-tubulin (BenA) and calmodulin (CaM) genes of the Aspergillus isolates were amplified and sequenced as previously described (Houbraken et al. 2011, 2012, Samson et al. 2019). The ITS regions, a part of the translation elongation factor 1 alpha $(T E F-1 \alpha)$ and/or the RNA polymerase II second largest subunit (RPB2) gene of all the other fungal species were amplified and sequenced in accordance with Groenewald et al. (2005), Groenewald et al. (2013), Chen et al. (2015), Chen et al. (2017) and O'Donnell et al. $(1998,2010)$. Additionally, partial fragments of the BenA, CaM, $T E F-1 a$ and RNA polymerase II largest subunit $(R P B 1)$ were generated for a subset of Fusarium strains, according to O'Donnell et al. $(1998,2009,2010)$ and Woudenberg et al. (2009). All generated sequences were compared with the sequences present in the NCBI database and internal curated databases of the Westerdijk Fungal Biodiversity Institute (WI) for confirmation of species identities. The identified isolates are maintained in the working culture collection of WI ("DTO culture collection") and in the 
culture collection of WI ("CBS culture collection”). All newly-generated sequences are deposited in GenBank (Suppl. material 1: Table S1).

To further explore the species diversity and determine the presence of putative novel taxa amongst the fusaria, phylogenetic analyses were carried out, based on $\operatorname{Ben} A$, $C a M, R P B 1, R P B 2$ and TEF-1a sequences. A first analysis, based on partial RPB2 sequences, was intended to determine the generic distribution of the Nigerian isolates. A second multi-locus analysis, based on the five gene regions above-mentioned, was used to determine the genetic exclusivity of an undescribed phylogenetic clade belonging to the Fusarium fujikuroi species complex (FFSC, O'Donnell et al. 2015, Choi et al. 2018). Additional sequences of type and reference strains were retrieved from GenBank and included in the analyses (Suppl. material 1: Table S2). Sequences of the individual loci were aligned using MAFFT v. 7.110 (Katoh et al. 2017). The individual gene datasets were assessed for incongruency prior to concatenation using a $70 \%$ reciprocal bootstrap criterion (Mason-Gamer and Kellogg 1996). Phylogenetic analyses were based on Maximum-Likelihood (ML) and Maximum-Parsimony (MP). For ML, randomised accelerated (sic) ML (RAxML) for high performance computing (Stamatakis 2014) was used on the CIPRES Science Gateway portal (Miller et al. 2012) and clade stability was tested with a bootstrap analysis (BS) using default parameters. For MP, PAUP (Phylogenetic Analysis Using Parsimony, v. 4.0b10; Swofford 2003) was used and phylogenetic relationships were estimated by heuristic searches with 1000 random addition sequences with tree-bisection-reconnection and branch swapping option set to 'best trees' only. All characters were weighted equally and alignment gaps treated as missing data. Tree length (TL), consistency index (CI), retention index (RI) and homoplasy index (HI) were calculated. Clade stability was assessed by bootstrap analyses, based on 1000 replications.

For extrolite profiling, each representative Aspergillus isolate was grown on Czapek yeast autolysate (CYA) agar, MEA and yeast extract sucrose (YES) agar and the selected Fusarium and Neocosmospora strains were grown on OA and PDA prior to extraction (Yilmaz et al. 2014, Samson et al. 2019). The culture media were incubated for 7 and $14 \mathrm{~d}$ at $25^{\circ} \mathrm{C}$. The agar plug extraction method of Filtenborg et al. (1983) with modifications as described by Smedsgaard (1997) was applied to extract cultural compounds. Extraction solvent for the agar plugs included ethylacetate/dichloromethane/methanol (3:2:1, v/v/v) containing 1\% formic acid. All extracts were air-dried prior to LC-MS/ MS screening as described below.

\section{LC-MS/MS extrolite analysis of agar plug extracts}

Extrolites of fungal cultures were determined by a dilute and shoot LC-MS/MS method (Sulyok et al. 2020). The air-dried extracts were dissolved in $1 \mathrm{ml}$ (ratio 1:1, v/v) of extraction solvent (acetonitrile/water/acetic acid 79:20:1, v/v/v) and then diluted with acetonitrile/water/acetic acid 20:79:1, v/v/v in a 1:1 (v/v) ratio prior to injection into the LC-MS/MS instrument. The QTrap 5500 LC-MS/MS System (Applied Biosys- 
tems, Foster City, CA, USA), equipped with TurbolonSpray electrospray ionisation (ESI) source and a 1290 Series HPLC System (Agilent, Waldbronn, Germany) was applied to screen the compounds. Chromatographic separation was performed at $25^{\circ} \mathrm{C}$ on a Gemini C18-column, $150 \times 4.6 \mathrm{~mm}$ i.d., $5 \mu \mathrm{m}$ particle size, equipped with a C18 $4 \times 3 \mathrm{~mm}$ i.d. security guard cartridge (Phenomenex, Torrance, CA, USA). The chromatographic method, chromatographic and mass spectrometric parameters are as described by Sulyok et al. (2020). ESI-MS/MS was conducted in the time-scheduled multiple reaction monitoring (MRM) mode both in positive and negative polarities in two separate chromatographic runs per sample by scanning two fragmentation reactions per analyte. The MRM detection window of each analyte was set to its expected retention time $\pm 20 \mathrm{~s}$ and $\pm 26 \mathrm{~s}$ in the positive and the negative modes, respectively. The identified positive analytes were confirmed by the acquisition of two MRMs per analyte. This yielded 4.0 identification points, according to European Commission decision 2002/657 (EC 2002). Additionally, the LC retention time and the intensity ratio of the two MRM transitions were in agreement with the related values of an authentic standard within $0.03 \mathrm{~min}$ and $30 \%$, respectively, following the criteria for mycotoxin identification as laid down in SANTE 12089/2016.

\section{Data analysis}

The IBM SPSS v21.0 (SPSS Inc., IL, USA) was applied for data analysis. Data on fungal load were first normalised by a logarithm to base 10 transformation of the original data prior to the calculation of mean values. Means were tested for significance by One-way ANOVA $(\alpha=0.05)$. Means of the concentrations $(\mu \mathrm{g} / \mathrm{kg})$ of the extrolites, produced by the fungal strains in culture media, were also calculated.

\section{Results and discussion}

\section{Distribution of fungi in food and soil}

Fungal propagules were recovered from $84 \%(n=209)$ of the 250 food samples and from all of the soil samples $(\mathrm{n}=30)$. The fungal load in the food samples was significantly $(p<0.05)$ higher at harvest (range: $2.00-6.22$; mean: $4.07 \pm 0.95 \log _{10} \mathrm{CFU} / \mathrm{g}$ ) than in storage (range: $2.00-4.60$; mean: $3.44 \pm 0.69 \log _{10} \mathrm{CFU} / \mathrm{g}$ ). The load of fungal propagules in the soil samples ranged 2.70-4.20 (mean: $3.45 \pm 0.34 \log _{10} \mathrm{CFU} / \mathrm{g}$ ). Variations observed in fungal load during the two seasons (harvest and storage) may be attributed to the sampling environment and nature of samples. For example, harvest samples were recently collected from the field where crops are in contact with soil and a large diversity of fungal propagules were present (Bankole et al. 2006), whereas storage conditions are often controlled (crops stored individually in local granaries), thereby leading to lower fungal densities (Williams et al. 2014). In addition, harvest 
samples were not yet "cleaned" (threshed or deshelled) and so harboured more viable fungal propagules compared to samples collected from storage bins which were already threshed, deshelled and bagged. A similar fungal load found in soil samples in the present study was previously reported for 55 soil samples collected from maize fields (range: $55-3736 \mathrm{CFU} / \mathrm{g}=1.74-3.57 \mathrm{Log}_{10} \mathrm{CFU} / \mathrm{g}$ ) across three agro-ecological zones of Nigeria (Donner et al. 2009). A total of 839 fungal isolates were recovered from the food and soil samples and grouped, based on similarities in phenotypic characters. Representative isolates $(\mathrm{n}=121)$ selected from the groups clustered into seven genera (Fig. 1) and 21 species (Fig. 2C), based on a polyphasic taxonomic scheme. The overall incidences of the recovered fungal genera in decreasing order of magnitude were: Aspergillus (60\%), Fusarium (17\%), Neotestudina (12\%), Neocosmospora (8\%), Phoma (2\%), Macrophomina (1\%) and Meyerozyma (1\%). The overall highest incidence of Aspergillus in the samples, as recorded in the present study, agrees with previous studies from different locations and substrates (Atehnkeng et al. 2008, Donner et al. 2009, Diedhiou et al. 2011, Makun et al. 2011, Ezekiel et al. 2013a, 2013b, 2016, 2019, Probst et al. 2014, Oyedele et al. 2017). To the best of our knowledge, we present the first report of Neotestudina from Nigerian soil.

Based on the fungal isolates recovered from food and soil samples and identified in this study, sample type-specific fungal incidences were estimated as $40.5 \%, 28 \%$, $14.9 \%, 9.9 \%, 4.9 \%$ and $1.7 \%$ in soil, maize, sorghum, groundnut, cowpea and rice, respectively. Aspergilli were widely distributed in soil and food, although a higher proportion of isolates (35.6\%) was recovered from soil compared to the individual foods. Nine Aspergillus species, belonging to two sections, were recovered in this study (Fig. 2). The species include: $A$. aflatoxiformans, $A$. austwickii, $A$. cerealis, $A$. flavus and $A$. tamarii in section Flavi (Frisvad et al. 2019) and A. brunneoviolaceus, A. niger, A. piperis

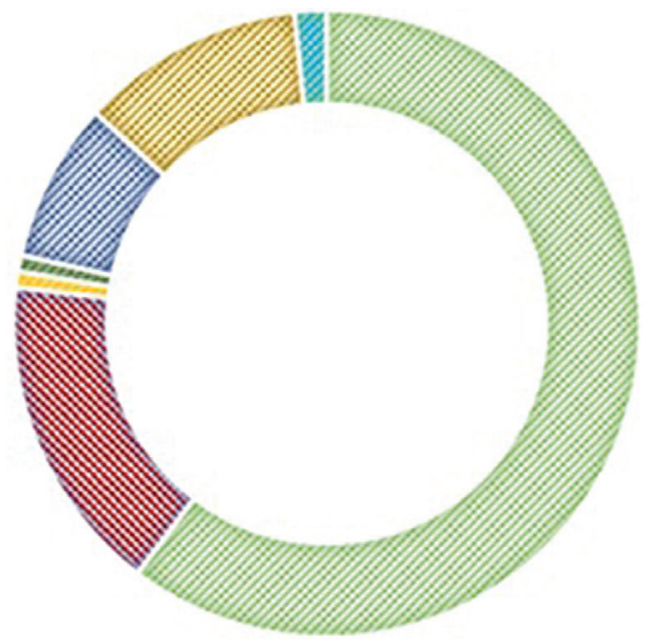

Aspergillus (60\%)

- Fusarium (17\%)

Macrophomina (1\%)

- Meyerozyma (1\%)

* Neocosmospora (8\%)

" Neotestudina (12\%)

s Phoma (2\%)

Figure I. Overall incidence of fungal genera recovered from food and soil in two states in north-central Nigeria. 


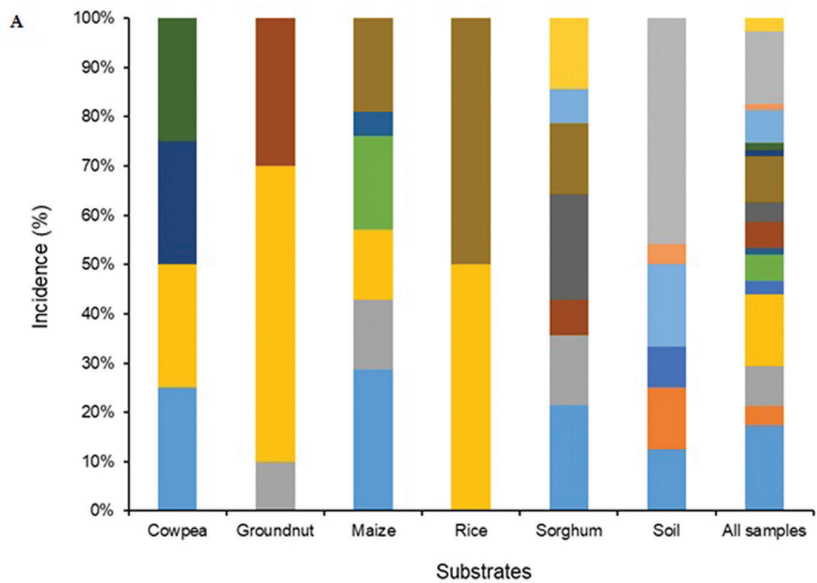

=Aspergillus aflatoxiformans

- Aspergillus brunneoviolaceus

=Aspergillus flavus

= Aspergillus niger

- Aspergillus piperis

$=$ Aspergillus tamarii

- Aspergillus vadensis

- Fusarium madaense sp. nov.

- Fusarium thapsinum

- Fusarium verticillioides

- Macrophomina phaseolina

- Meyerozyma caribbica

= Neocosmospora falciformis

= Neocosmospora suttoniana

= Neotestudina rosatii

=Phoma species

B

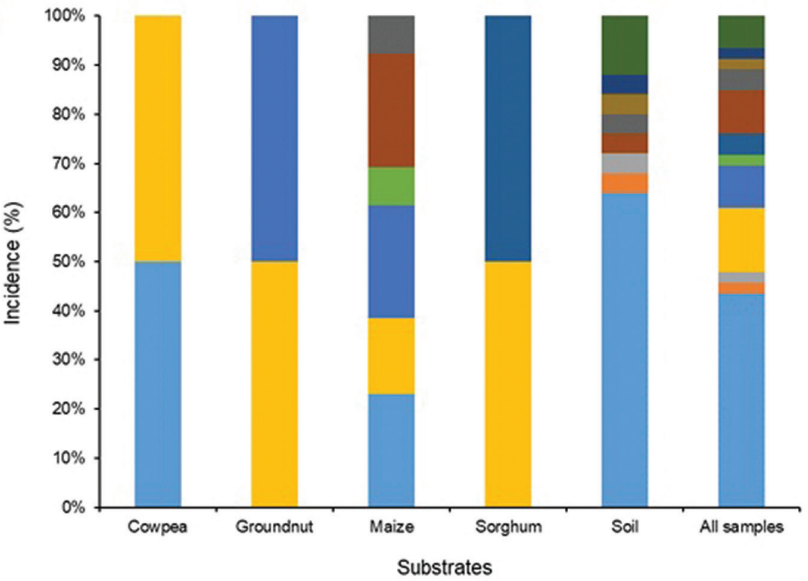

= Aspergillus aflatoxiformans

= Aspergillus austwickii

" Aspergillus cerealis

"Aspergillus flavus

" Aspergillus tamarii

" Aspergillus vadensis

- Fusarium andiyazi

n Fusarium verticillioides

n Neocosmospora falciformis

- Neocosmospora ipomceae

- Neocosmospora vasinfecta

- Neotestudina rosatii

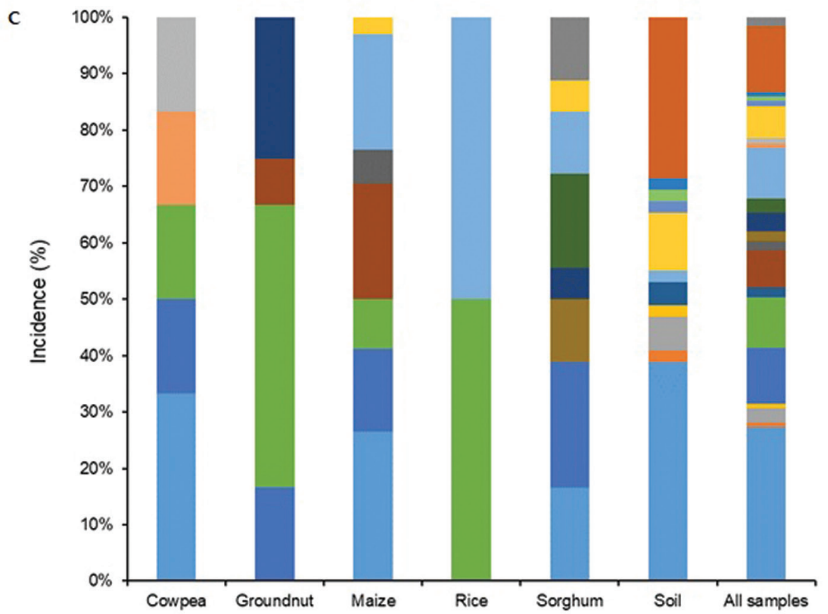

= Aspergillus aflatoxiformans

= Aspergillus austwickii

= Aspergillus brunneoviolaceus

= Aspergillus cerealis

" Aspergillus flavus

= Aspergillus niger

- Aspergillus piperis

$\because$ Aspergillus tamarii

- Aspergillus vadensis

" Fusarium andiyazi

- Fusarium madaense sp. nov.

a Fusarium thapsinum

« Fusarium verticillioides

Macrophomina phaseolina

= Meyerozyma caribbica

= Neocosmospora falciformis

$=$ Neocosmospora ipomoeae

= Neocosmospora suttoniana

= Neocosmospora vasinfecta

$=$ Neotestudina rosatii

- Phoma species

\section{Substrates}

Figure 2. Distribution of fungal species in food and soil in two states $\mathbf{A}$ Nasarawa state B Niger state

C combined/both states) in north-central Nigeria. 
and A. vadensis in section Nigri (Samson et al. 2007, Perrone et al. 2011, Varga et al. 2011). Aspergillus aflatoxiformans $(27.3 \%)$ was the predominant species found in this study, based on the identified representative isolates (Fig. 2C). However, the predominance of $A$. aflatoxiformans here contradicts several previous reports that presented $A$. flavus as the predominant Aspergillus species in food and crops in Nigeria and elsewhere (Atehnkeng et al. 2008, Donner et al. 2009, Ezekiel et al. 2013a, 2013b, 2016, 2019, Probst et al. 2014, Oyedele et al. 2017). The disparity between our finding and previous reports is explainable and owes to bias during sub-culturing and selection of fungal isolates for molecular identification as less emphasis was given to A. flavus isolates. With respect to location, $A$. austwickii and $A$. cerealis were recovered only from soil in Niger state, while $A$. brunneoviolaceus, $A$. niger and $A$. piperis were recovered only in food and soil from Nasarawa state. Here, we present for the first time, A. vadensis as isolates from Nigerian food.

Four Fusarium species (F andiyazi, F. madaense sp. nov., $F$. thapsinum and $F$ verticillioides), belonging to FFSC, were identified. All the Fusarium spp. were recovered from food samples, except $F$. verticillioides that was found in both food (maize, rice and sorghum) and soil (Fig. 2C). Fusarium andiyazi was isolated from sorghum in the Nasarawa state (Fig. 2A), F. andiyazi was specific to sorghum from Niger state (Fig. 2B) and $F$. madaense sp. nov. was recovered from groundnut and sorghum from Nasarawa state (Fig. 2A). The diversity of Fusarium observed in this study is remarkable, as we present unique occurrences of $F$. madaense sp. nov. and $F$. thapsinum from Nigerian grains, in addition to the previously reported $F$. andiyazi and $F$. verticillioides (Marley et al. 2004, Afolabi et al. 2006, Makun et al. 2009, 2011). Fusarium verticillioides and other members of the FFSC, including those found in the present study ( $F$ andiyazi, F. proliferatum, F. pseudonygamai, F. subglutinans and F. thapsinum), have been documented in cereals and natural environments in different countries (Fandohan et al. 2005, Ncube et al. 2011, Leyva-Madrigal et al. 2014, O’Donnell et al. 2015, Moussa et al. 2017, Choi et al. 2018, Chala et al. 2019). The specificity of $F$. andiyazi and $F$. thapsinum to sorghum, which we observed here, agrees with literature (Marley et al. 2004, Pena et al. 2018, Chala et al. 2019). The additional discovery of $F$. madaense sp. nov. in groundnut and sorghum in this study emphasises the need to adopt adequate and robust characterisation approaches in fungal studies, as well as to conduct largescale fungal biodiversity studies of food and soil in the country.

Macrophomina phaseolina, Meyerozyma caribbica and Phoma species were isolated only from food in Nasarawa state (Fig. 2A, C). Macrophomina phaseolina and M. caribbica were specific to cowpea, while Phoma species were recovered from sorghum. Macrophomina phaseolina is a common pathogen of legumes, including cowpea and causes charcoal rot and root rot (Amusa et al. 2007, Oladimeji et al. 2012, Sarr et al. 2014, Khan et al. 2017). Meyerozyma caribbica (anamorph Candida fermentati) is a halophilic and rhizospheric yeast with biological control potential against phytopathogenic fungi (Bautista-Rosales et al. 2013), while Phoma is a genus of mostly phytopathogens (Chen et al. 2015, 2017). Future studies may explore the role of M. caribbica in biological control of mycotoxigenic fungi found in this study. Neotestudina rosatii was present 
only in soil (Fig. 2C). This fungus was actually first described in Africa in 1961 as the agent for maduromycosis (Segretain and Destombes 1961) and has been associated with the same human disease in two African countries, Senegal and Somalia (Baylet et al. 1968, Destombes et al. 1977). Four species of Neocosmospora ( $N$. falciformis, $N$. ipomoeae, N. suttoniana and $N$. vasinfecta) were recovered from food and soil (Fig. 2C). Neocosmospora ipomoeae and $N$. vasinfecta and $N$. suttoniana were specific only to soils in Niger and Nasarawa states, respectively, while $N$. falciformis was found in food and soil in both states (Fig. 2A, B). Neocosmospora (formerly 'Fusarium' solani species complex, FSSC) comprises common pathogens of plants, humans and animals (Sandoval-Denis and Crous 2018). For example, N. falciformis (syn. F. falciforme) is known to be associated with diverse cutaneous and subcutaneous fungal infections (Dignani and Anaissie 2004, Garcia et al. 2015). This species is frequently found in equine ocular infections and in canines and reptiles (O'Donnell et al. 2016). Recently, Sandoval-Denis and Crous (2018) described N. suttoniana; this species is implicated in uncommon human eye infections in Africa and the USA (O'Donnell et al. 2008).

\section{Extrolites produced in fungal cultures}

The elucidation of extrolite patterns from fungal strains grown on mycological media, using the highly sensitive LC-MS/MS technique, remains the gold standard chemotaxonomic approach to fungal characterisation (Frisvad et al. 2007, 2018, Samson et al. 2019). In this study, extrolite production in solid media was examined by LC-MS/ MS in strains belonging to 20 of the 21 identified fungal species. Cultures of $A$. tamarii and $M$. phaseolina were not included in extrolite analysis. Whereas all compounds were quantitatively determined, aflatrem, asparason A, aspulvinone E, aurasperons, desoxypaxillin, fonsecin, nigragillin, paspalin, paspalinin, paspalitrems and tensidol B were only semi-quantified in the cultures due to lack of a quantitative standard. All the examined fungal strains/species produced at least three (Tables 1,2) and as many as 33 compounds in $A$. aflatoxiformans (Table 1). Brevianamid F and cyclo(LPro-L-Tyr) were detected in examined cultures and cyclo(L-Pro-L-Val) was present in all except three Neocosmospora species ( $N$. falciformis, $N$. ipomoeae and $N$. suttoniana). These three compounds, found in almost all fungal species in this study, were the only metabolites detected in cultures of $M$. caribbica and Phoma sp. in addition to tryptophol in M. caribbica (data not shown). Brevianamid F, cyclo(L-Pro-L-Tyr) and cyclo(LPro-L-Val) were previously reported in cultures of $A$. niger, $A$. tamarii, Paecilomyces and Talaromyces from cocoa beans processing in Nigeria (Akinfala et al. 2020).

\section{Aspergillus metabolites}

The extrolite patterns of the Aspergillus species, isolated and identified in this study, except $A$. tamarii which was not evaluated, are shown in Table 1 . Members of the section Flavi produced metabolites (aflatoxins and their biosynthetic pathway precursors, 
asparason A, cyclopiazonic acid, desoxypaxillin, kojic acid, kotanin A, paspalin and paspalitrems) consistent with previous reports (Frisvad et al. 2019, Uka et al. 2019, Ezekiel et al. 2020). However, some new findings are reported herein. For example, desoxypaxillin, heptelidic acid, kotanin A and paspalitrems were previously reported in A. flavus (Uka et al. 2019, Kovac et al. 2020, Ezekiel et al. 2020), but not in $A$. aflatoxiformans, $A$. austwickii and $A$. cerealis. Hence, we present the first report of desoxypaxillin, kotanin A (mean: $534 \mu \mathrm{g} / \mathrm{kg}$ ) and paspalitrems in the three S-type sclerotium (minisclerotium) producing species and heptelidic acid $(10.2 \mathrm{mg} / \mathrm{kg})$ only in $A$. austwickii. In addition, averantinmethylether $(9.4 \mu \mathrm{g} / \mathrm{kg})$ and aspergillimide $(21.3 \mu \mathrm{g} /$ $\mathrm{kg}$ ) are two uncommon compounds found only in cultures of one strain of A. aflatoxiformans and A. flavus, respectively. Similar to a recent report (Ezekiel et al. 2020), two of the four A. flavus strains, examined in this study, produced sporogen AO1 (mean: $974 \mu \mathrm{g} / \mathrm{kg}$ ), confirming the production of this compound in A. flavus. One of the four A. flavus strains, DTO 421-G6, did not produce aflatoxins, any of its pathway metabolites, cyclopiazonic acid or kojic acid, but produced cyclosporins A, B, C and H. Cyclosporin production has been reported in Aspergillus terreus (Sallam et al. 2003), Neocosmospora solani (Sawai et al. 1981) and Tolypocladium (El-Enshasy et al. 2008). It is, therefore, suggested that strain DTO 421-G6, whose origin is sorghum grain from Sabon Wuse in Niger state, may be a prospective candidate for biological control of aflatoxins in view of its inability to biosynthesise aflatoxins, its pathway metabolites and cyclopiazonic acid. The biological control product, aflasafe, commercially available for aflatoxin control in Nigeria, contains strains of A. flavus original to Niger state and which possesses a similar inability to secrete the aforementioned metabolites (Bandyopadhyay et al. 2016, 2019).

The members of Aspergillus section Nigri (A. brunneoviolaceus, A. niger, A. piperis and $A$. vadensis) secreted a total of 31 extrolites (Table 1 ). However, only three extrolites, aurasperons, nigragillin and pyrophen, were common to all four species within this section. Varga et al. (2011) placed A. brunneoviolaceus in the A. aculeatus clade, whilst $A$. niger, $A$. piperis and $A$. vadensis were grouped into the $A$. niger clade. In the present study, members of the $A$. niger clade shared only four (aspulvinone $\mathrm{E}$, fonsecin, malformins and pyranonigrin) of the compounds. Obviously, high variability in the types of metabolites produced was recorded amongst these closely-related species (Frisvad et al. 2007, Samson et al. 2007). Strains of A. brunneoviolaceus (syn. A. fijiensis) liberated several known extrolites: aspergillimide (mean: $30.1 \mathrm{mg} / \mathrm{kg}$ ), emodin (mean: $541 \mu \mathrm{g} /$ $\mathrm{kg}$ ), endocrocin (mean: $23 \mathrm{mg} / \mathrm{kg}$ ), iso-rhodoptilometrin (mean: $340 \mu \mathrm{g} / \mathrm{kg}$ ), meleagrin (mean: $7.6 \mathrm{mg} / \mathrm{kg}$ ), oxaline (mean: $17.3 \mathrm{mg} / \mathrm{kg}$ ), paraherquamide $\mathrm{E}$ (mean: $6 \mathrm{mg} / \mathrm{kg}$ ) and secalonic acid D (mean: $64.7 \mathrm{mg} / \mathrm{kg}$ ) (Varga et al. 2011, Vesth et al. 2018, Ezekiel et al. 2020). However, citreorosein and tryprostatin B, two compounds recently reported to be produced by A. brunneoviolaceus from garri (farinated cassava) in Nigeria (Ezekiel et al. 2020), were not detected in cultures of the present strains. Nonetheless, six uncommon compounds (aurasperon C, dimethylsulochrin (mean: $1.9 \mathrm{mg} / \mathrm{kg}$ ), fellutanine A $(152 \mu \mathrm{g} / \mathrm{kg}$ ), methylorsellinic acid (mean: $1.2 \mathrm{mg} / \mathrm{kg}$ ), nigragillin and pyrophen (mean: $190 \mu \mathrm{g} / \mathrm{kg})$ ) were produced by strains examined in the present study. Of 


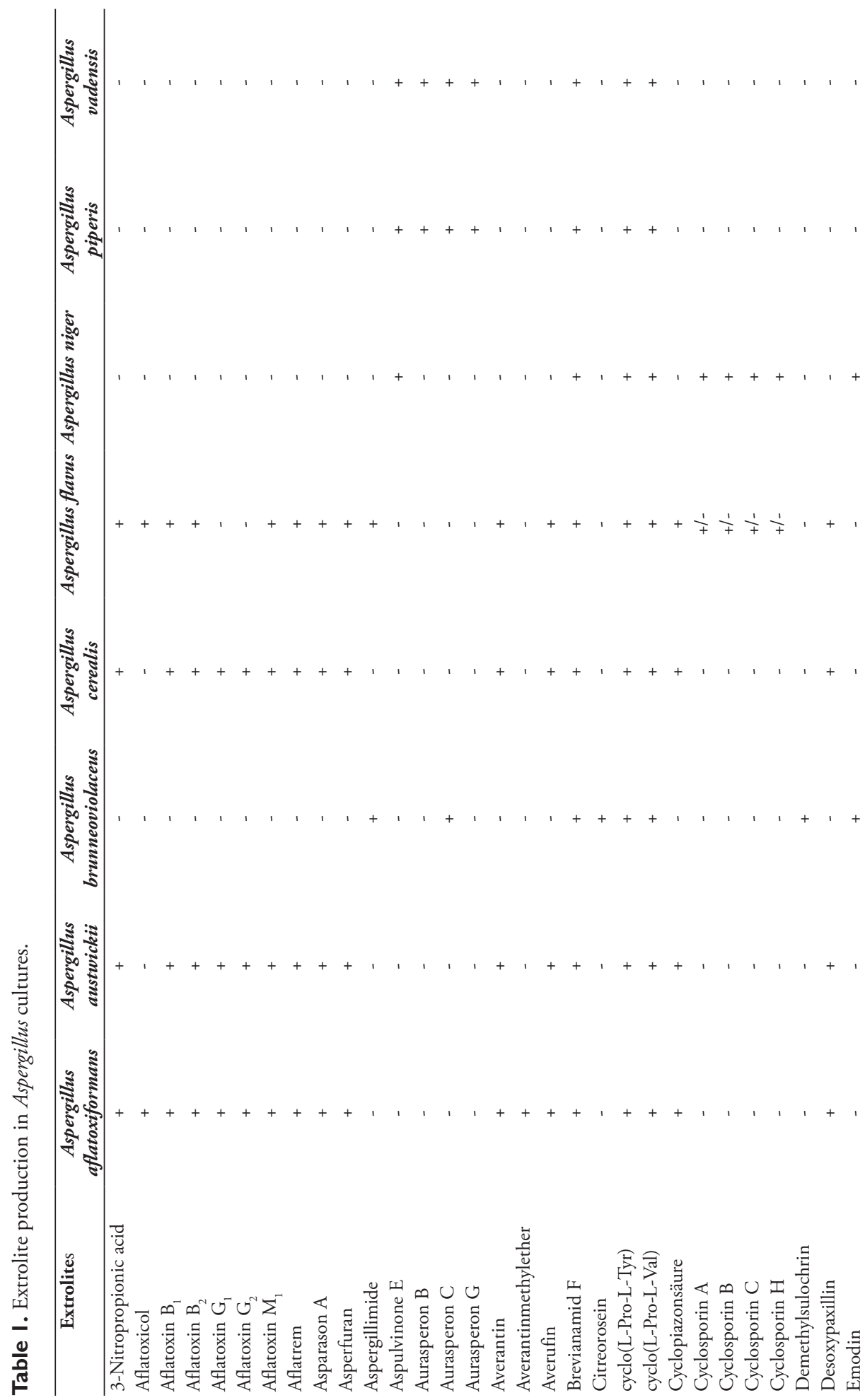




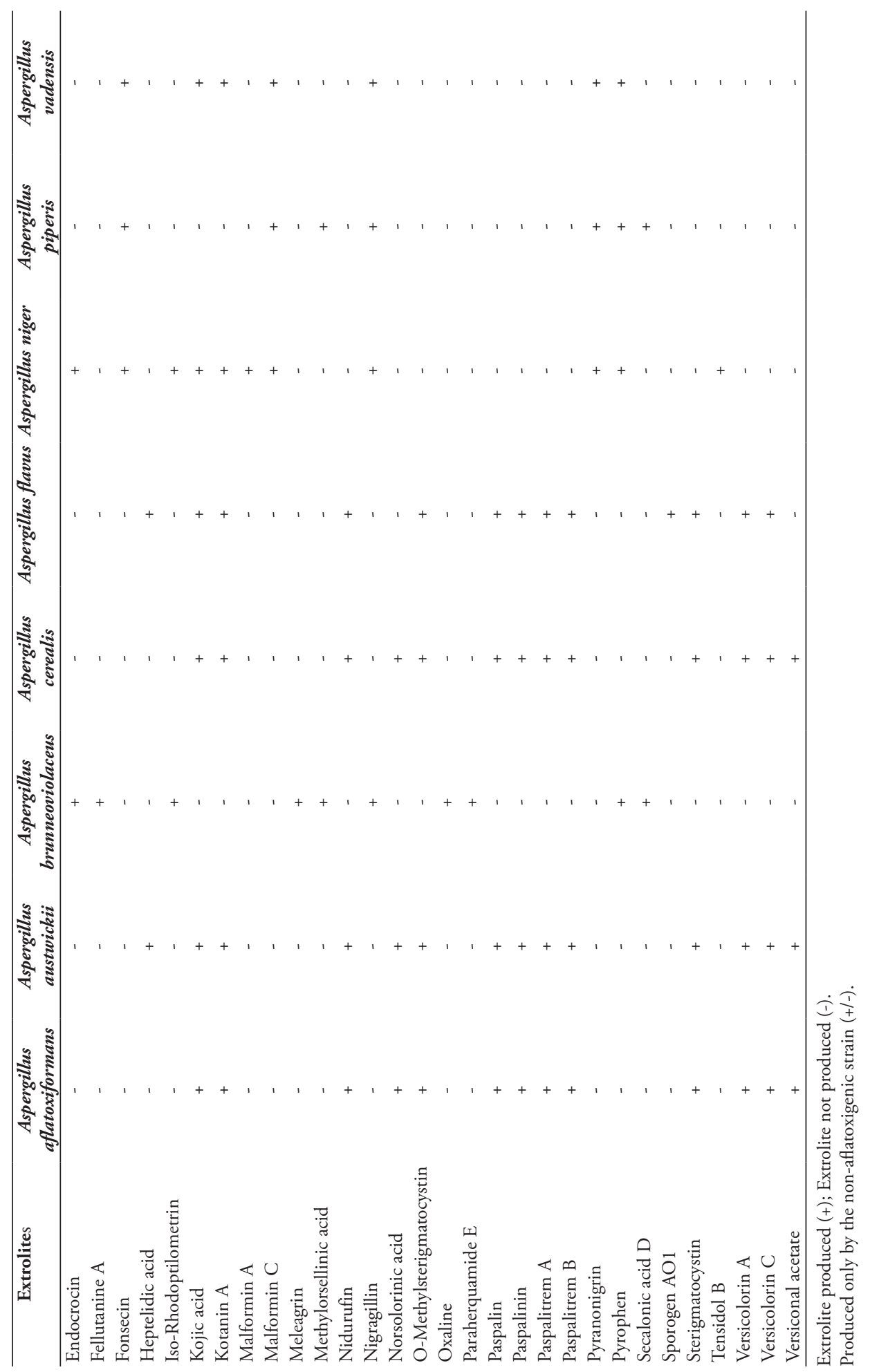


all the extrolites found in cultures of the four species within the section Nigri, aspergillimide, dimethylsulochrin, fellutanine $\mathrm{A}$, meleagrin, oxaline and paraherquamide $\mathrm{E}$ were specific to only $A$. brunneoviolaceus, whilst cyclosporins (A, B, $\mathrm{C}$ and $\mathrm{H}$ ) and tensidol $\mathrm{B}$ were unique to $A$. niger. This is the first report of cyclosporin production in $A$. niger; only $2 / 9$ of the strains, DTO 422-H5 and DTO 422-H6, were implicated here. In addition, we observed emodin $(48 \mu \mathrm{g} / \mathrm{kg})$ and endocrocin $(262 \mu \mathrm{g} / \mathrm{kg})$ production in only one strain (DTO 421-I7) of $A$. niger. All other compounds found in cultures of $A$. niger in the present study are known extrolites (de Vries et al. 2005, Samson et al. 2007, Nielsen et al. 2009, Perrone et al. 2011, Akinfala et al. 2020).

Two strains of $A$. piperis, screened in this study, secreted compounds agreeable to those previously documented in literature (Samson et al. 2007, Ezekiel et al. 2020). Amongst the extrolites found in the present study are those being reported here for the first time in A. piperis: methylorsellinic acid (mean: $1.7 \mathrm{mg} / \mathrm{kg}$ ), pyrophen (mean: $50 \mathrm{mg} /$ $\mathrm{kg}$ ) and secalonic acid $(24.3 \mu \mathrm{g} / \mathrm{kg}$ ) (Table 1). de Vries et al. (2005) examined extrolite production in one strain of $A$. vadensis and found aurasperon $\mathrm{B}$, asperazine, nigragillin and a more polar kotanin-like compound. Here, we report aspulvinone $\mathrm{E}$, aurasperons (B, C and G), fonsecin, kojic acid (mean: $281 \mu \mathrm{g} / \mathrm{kg}$ ), kotanin A (91 $\mu \mathrm{g} / \mathrm{kg}$ ), malformin $\mathrm{C}$ (mean: $857 \mu \mathrm{g} / \mathrm{kg}$ ), nigragillin, pyranonigrin (mean: $72 \mathrm{mg} / \mathrm{kg}$ ) and pyrophen (mean: $52.4 \mathrm{mg} / \mathrm{kg}$ ). The complexity in small molecule chemical profiles observed in the species belonging to the section Nigri suggests a high degree of close-relatedness amongst these species (Samson et al. 2007, Nielsen et al. 2009, Perrone et al. 2011).

\section{Extrolites from Fusarium and its related fungal species}

A total of 15, 12 and 11 extrolites were found in cultures of Fusarium, Neocosmospora and Neotestudina (Table 2). With the exception of $N$. vasinfecta, gibepyron D production was shared by all examined strains of these three genera; higher quantities were found in cultures of F. madaense sp. nov. (mean: $4.9 \mathrm{mg} / \mathrm{kg}$ ) and $F$. thapsinum (mean: $4.2 \mathrm{mg} / \mathrm{kg}$ ). Gibepyron D is an oxidised derivative of gibepyrone A that has been reported in F. fujikuroi, F. oxysporum and F. proliferatum (Wang et al. 2011, Liu et al. 2013, Janevska et al. 2016). Thus, its production by three fungal genera suggests ancestral relatedness of a gene cluster encoding production of this compound (Janevska et al. 2016). Fumonisins ( $\mathrm{FA}_{1}$ (mean: $616 \mu \mathrm{g} / \mathrm{kg}$ ), $\mathrm{FB}_{1}$ (mean: $3.4 \mathrm{mg} / \mathrm{kg}$ ), FB (mean: $^{2}$ $2 \mathrm{mg} / \mathrm{kg}$ ) and $\mathrm{FB}_{3}$ (mean: $1.4 \mathrm{mg} / \mathrm{kg}$ )), fusarin $\mathrm{C}$ (mean: $27 \mathrm{mg} / \mathrm{kg}$ ) and fusarinolic acid (mean: $84,856 \mathrm{mg} / \mathrm{kg}$ ) were exclusively produced by the Fusarium species examined in this study. Fumonisins were produced as expected only by $F$. verticillioides, although the cultures of two strains, DTO 421-G2 and DTO 424-H5, did not contain any of the fumonisins. Fumonisin production is a signature in this species as well as in other selected members of the FFSC not found in the present study (Makun et al. 2011, Ncube et al. 2011, de Oliveira Rocha et al. 2011, Fanelli et al. 2012, Rocha et al. 2016, Choi et al. 2018).

All the species of Fusarium, except $F$ andiyazi, produced fusarin $C$ in this study. Beauvericin, bikaverin, deoxyfusapyron and fusapyron were found in cultures of certain 


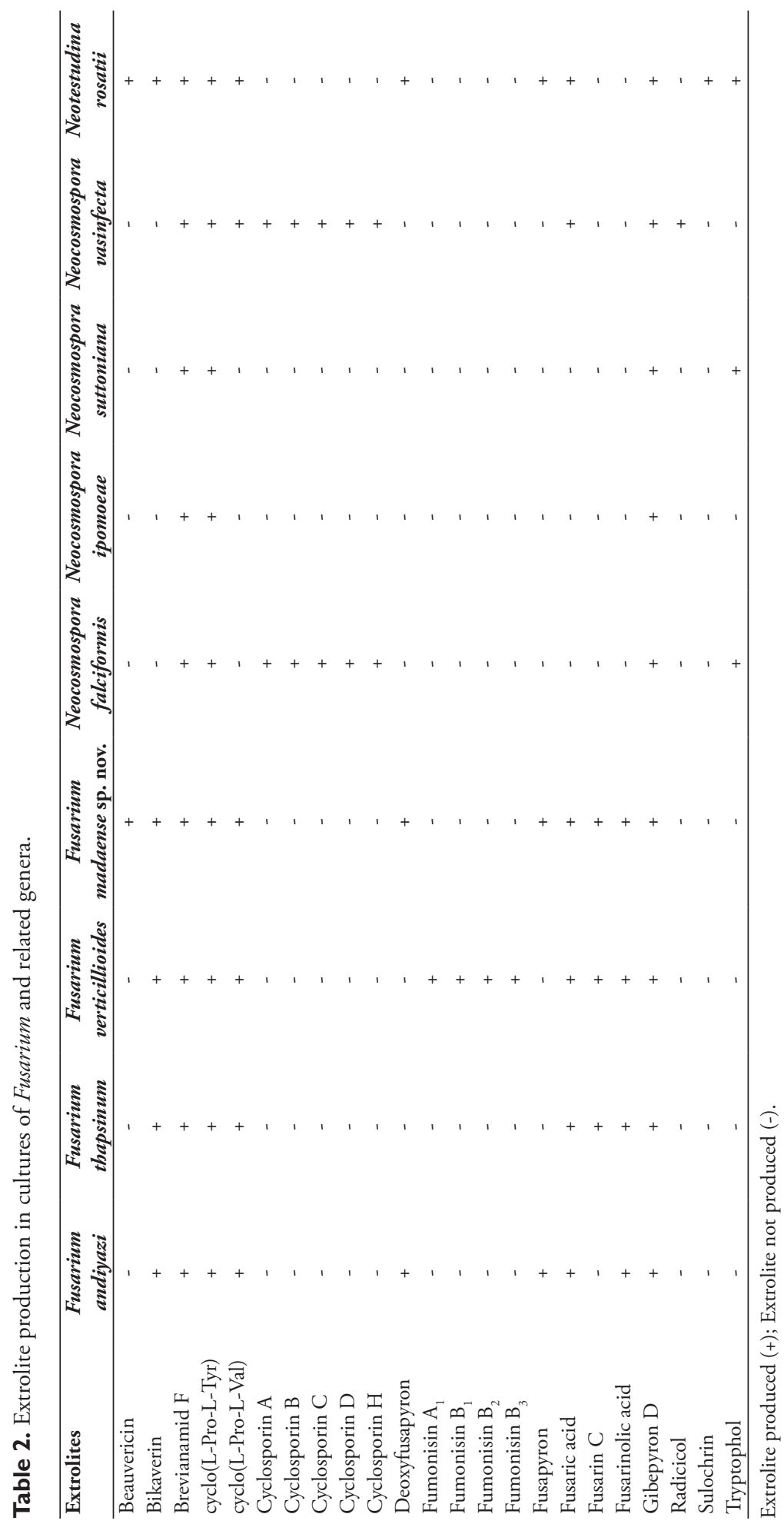


species of Fusarium, Neocosmospora and Neotestudina. Specifically, F. madaense sp. nov. and $N$. rosatii produced all four aforementioned compounds together with the other three species of Fusarium for bikaverin and $F$ andiyazi for deoxyfusapyron and fusapyron. The immunosuppressant cyclosporins [A (mean: $42.2 \mathrm{mg} / \mathrm{kg}$ ), B (mean: $27.3 \mathrm{mg}$ / kg), C (mean: $29.9 \mathrm{mg} / \mathrm{kg}$ ), D (mean: $4.6 \mathrm{mg} / \mathrm{kg}$ ) and $\mathrm{H}$ (mean: $32.9 \mathrm{mg} / \mathrm{kg}$ )] were specific to Neocosmospora and were found only in cultures of $N$. falciformis and $N$. vasinfecta. Radicicol $(323 \mathrm{mg} / \mathrm{kg})$ and sulochrin $(1.8 \mathrm{mg} / \mathrm{kg})$ were found in one strain of $N$. vasinfecta and $N$. rosatii, respectively. Based on the recorded chemical profiles in this study, the three studied genera are closely related chemotaxonomically. However, $F$. madaense sp. nov. and $N$. rosatii seem to be more closely related than the other species. This is the first chemotaxonomic profiling of F. madaense sp. nov., Meyerozyma, Neocosmospora and Neotestudina.

Phylogenetic analyses of Fusarium and Neocosmospora and description of a novel Fusarium species

A first phylogenetic analysis, based on partial RPB2 sequences, was conducted to identify Nigerian isolates morphologically compatible with Fusarium and Neocosmospora spp. (Fig. 3). The analysis included 659 positions of 78 isolates, including the two outgroup taxa (Fusicolla aquaeductuum NRRL 20686 and Fusicolla sp. NRRL 22136), of which 284 bp were constant sites, 375 bp were variable and 336 bp were parsimonyinformative. The ingroup taxa included representative isolates of 40 species from 17 species complexes of Fusarium and seven species of Neocosmospora. Four isolates (CBS $146648,146651,146656$ and 146669) clustered in a partially supported, putative novel clade, closely related to $F$ andiyazi; the latter taxon, however, clustered in an unresolved phylogenetic position.

To further determine the relationship between the putative novel clade and $F$ andiyazi, a second analysis was conducted which encompassed 4456 positions of five loci (BenA 525 bp, CaM 545 bp, RPB1 978 bp, RPB2 1735 bp and TEF-1a 673 bp), of which 3417 were constant (BenA 406 bp, CaM 421 bp, RPB1 777 bp, RPB2 1379 bp and TEF-1a 434 bp), 1018 were variable (BenA 118 bp, CaM 120 bp, RPB1 201 bp, $R P B 2356$ bp and TEF-1a 223 bp) and 614 were parsimony informative (BenA 64 bp, CaM 63 bp, RPB1 132 bp, RPB2 236 bp and TEF-1a 119 bp). The final alignment included 44 isolates, representing 35 Fusarium spp. from the three biogeographical phylogenetic clades of FFSC (African, American and Asian clades, O'Donnell et al. 1998) plus two outgroups (F. oxysporum NRRL 20433 and NRRL 22902) (Fig. 4). The multi-locus phylogeny confirmed the previous results. The putative novel clade (CBS 146648, 146651, 146656 and 146669) was resolved as a fully supported phylogenetic lineage $(\mathrm{MP} B S=100, \mathrm{ML} B S=100)$, sister to a moderately-supported clade (MP BS 97, ML BS 100), encompassing the ex-type strain of $F$ andiyazi (CBS 119857), plus four additional representative isolates of the latter species, two of them (CBS 146647 and 146657) being obtained in this study. The novel phylogenetic lineage is here recognised as Fusarium madaense sp. nov. 


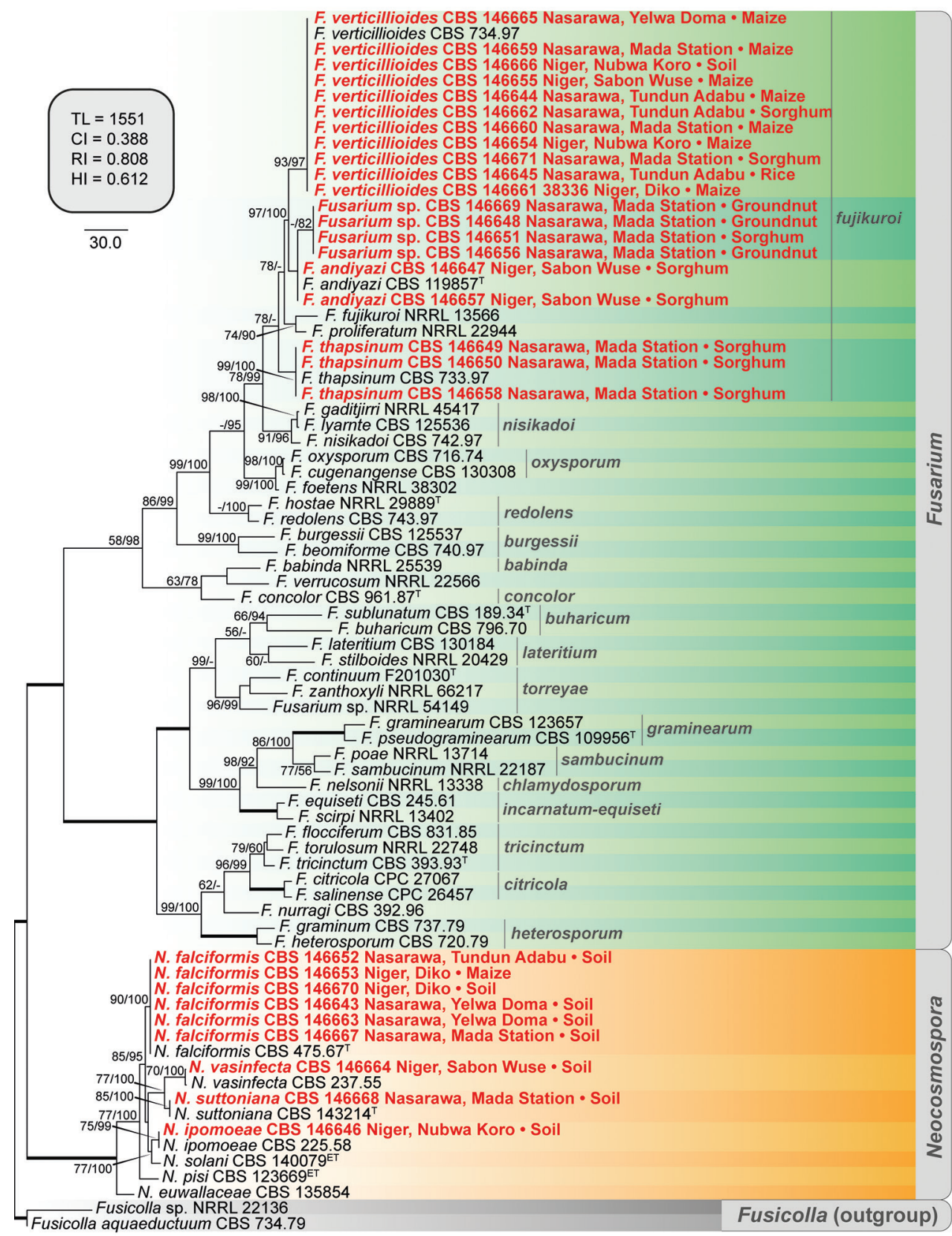

Figure 3. The first of 1000 equally parsimonious trees obtained from Maximum-Parsimony (MP) analysis of RPB2 sequences of 76 isolates of Fusarium and Neocosmospora spp. Numbers on the nodes are MP bootstrap values (BS) and Maximum-Likelihood BS values above 70\%. Branch lengths are proportional to distance. Ex-type and ex-epitype strains are indicated with ${ }^{\mathrm{T}}$ and ${ }^{\mathrm{ET}}$, respectively. The names of 17 species complexes of Fusarium are shown in grey. Nigerian isolates obtained in this study are shown in red together with their geographical origin and source of isolation. The internal square shows MP statistics as follows: $\mathrm{TL}=$ tree length, $\mathrm{CI}=$ consistency index, $\mathrm{RI}=$ retention index and $\mathrm{HI}=$ homoplasy index . 


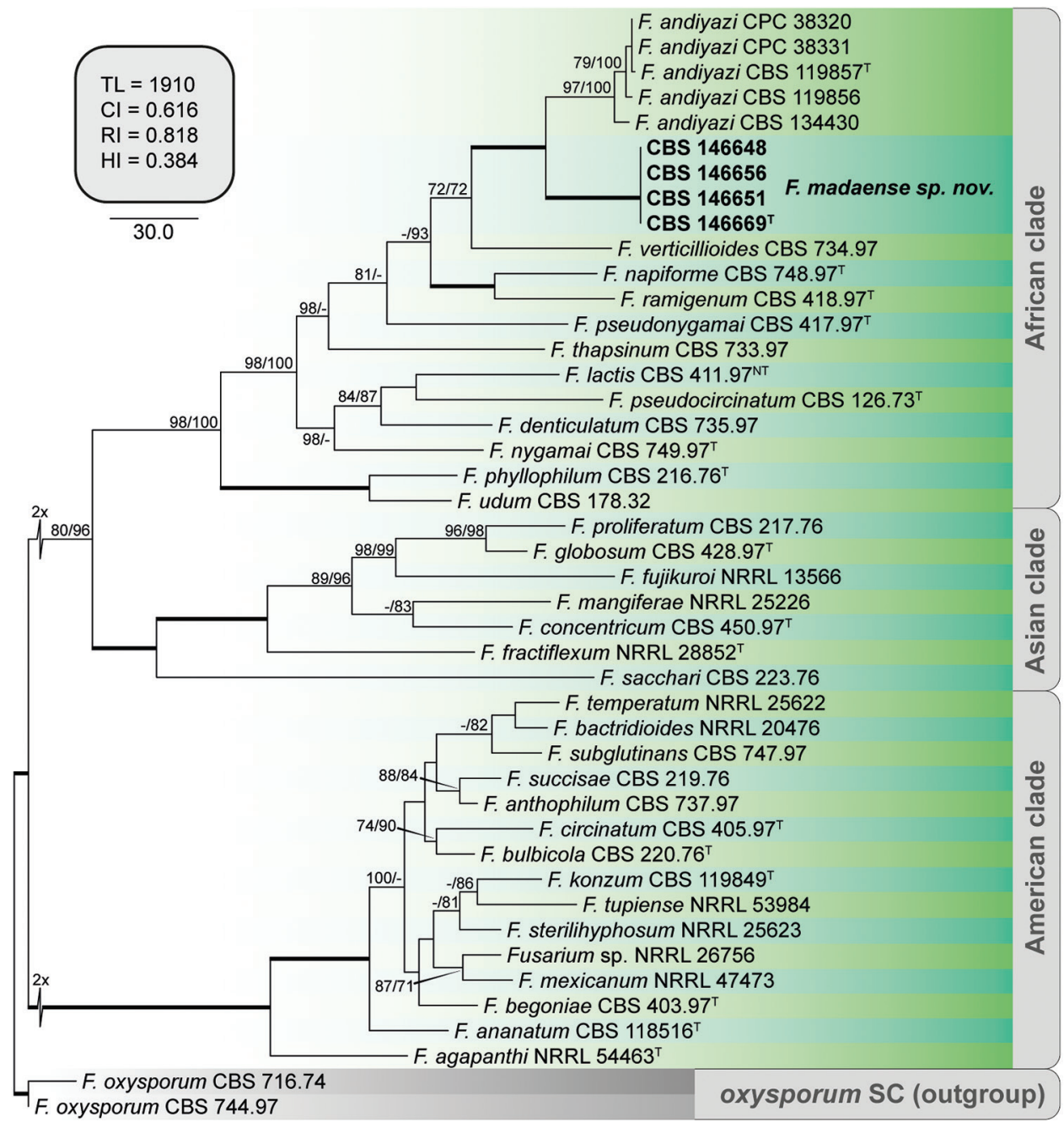

Figure 4. The first of 24 equally parsimonious trees obtained from Maximum-Parsimony (MP) analysis of BenA, CaM, RPB1, RPB2 and TEF-1a sequences of 42 isolates of Fusarium spp. Numbers on the nodes are MP bootstrap values (BS) and Maximum-Likelihood BS values above $70 \%$. Branch lengths are proportional to distance. Ex-type strains are indicated with ${ }^{\mathrm{T}}$. Strains corresponding to new species described here are shown in bold. The internal square shows MP statistics as follows: $\mathrm{TL}=$ tree length, $\mathrm{CI}=$ consistency index, $\mathrm{RI}=$ retention index and $\mathrm{HI}=$ homoplasy index.

\section{Taxonomy}

\section{Fusarium madaense Ezekiel, Sand.-Den., Houbraken \& Crous, sp. nov.}

MycoBank No: MB835266

Figure 5

Diagnosis. Different from $F$. thapsinum by the absence of napiform microconidia. Different from $F$. andiyazi, $F$. thapsinum and $F$. verticillioides by its lighter colony pig- 
mentation, growth rates, microconidial septation, presence of true chlamydospores and secondary metabolite patterns.

Type. Nigeria, Nasarawa, Mada Station, from groundnut (Arachis hypogaea), Sep. 2018, C.N. Ezekiel, holotype CBS H-24346, ex-holotype strain CBS 146669 = CPC $38344=12 \mathrm{~B}(3) 2$.

Description. Colonies grown in the dark at $24^{\circ} \mathrm{C}$. On MEA and PDA with an average radial growth rate of 5.9-6.5 mm/d and filling an entire $90 \mathrm{~mm}$ Petri dish in $7 \mathrm{~d}$. Surface white to pale rosy buff, flat, velvety to felty with abundant patches of white aerial mycelium; margin regular, filiform. Reverse pale saffron to peach, a pale bay diffusible pigment can be scarcely produced. On OA, occupying an entire $90 \mathrm{~mm}$ Petri dish in $7 \mathrm{~d}$. Surface white to pale rosy buff, flat, velvety to felty with abundant patches of white aerial mycelium; margin regular. Reverse pale luteous to saffron. On SNA, reaching 24-25 mm diam. in $7 \mathrm{~d}$. Surface white, velvety, with scarce aerial mycelium, margins filiform. Reverse white.

Conidiophores on aerial mycelium straight, erect, septate, smooth- and thin-walled, commonly simple or reduced to conidiogenous cells, borne laterally on hyphae or laterally branched at various levels, bearing terminal single monophialides; phialides subulate to subcylindrical, smooth- and thin-walled, (17-)25.5-39.5 $\mu \mathrm{m}$ long, (2-)2.5$3.5 \mu \mathrm{m}$ at widest point, periclinal thickening and collarettes inconspicuous or absent; microconidia hyaline, clavate, smooth- and thin-walled, 0-3-septate, (7-)9-15(-21) $\times$ (2-)2.5-4(-5) $\mu \mathrm{m}$, arranged in long chains at the tip of monophialides. Sporodochia pale to bright orange, formed abundantly on the surface of carnation leaves and on agar surface. Conidiophores in sporodochia, 21-60 $\mu \mathrm{m}$ tall, simple or irregularly and verticillately branched, bearing terminal, single monophialides or groups up 2-3 monophialides; sporodochial phialides doliiform to subcylindrical, (10.5-)13-18(-20.5) $\times$ (2.5-)3-4(-4.5) $\mu \mathrm{m}$, smooth- and thin-walled, with conspicuous periclinal thickening and an often short apical collarette. Sporodochial conidia lunate to falcate, tapering towards apical and basal ends, moderately curved dorsiventrally or with an almost straight ventral part; apical cell more or less equally sized than the adjacent cell, apically slightly elongated to papillate; basal cell distinctly notched, (0-)1-5(-6)-septate, hyaline, thin- and smooth-walled. Aseptate conidia: $(38-) 38.5-42(-44) \times 3.5-4.5 \mu \mathrm{m}$; one-septate conidia: $(37.5-) 40-48(-53) \times 3.5-4(-4.5) \mu \mathrm{m}$; two-septate conidia: $43 \times$ $3.7 \mu \mathrm{m}$; three-septate conidia: (29-)38-48.5(-61.5) $\times(3-) 4-4.5(-5) \mu \mathrm{m}$; four-septate conidia: (45-)46.5-54(-59) $\times(3.5-) 4-4.5(-5) \mu \mathrm{m}$; five-septate conidia: 47.5-55.5($60) \times 4-4.5 \mu \mathrm{m}$; six-septate conidia: $55.5 \times 4.5 \mu \mathrm{m}$; overall (29-)38.5-50(-61.5) $\times$ (3-)4-4.5(-5) $\mu \mathrm{m}$. Chlamydospores present on MEA, PDA and SNA, globose to subglobose, hyaline, smooth and thick-walled, (6-)6.5-8.5(-10) $\mu \mathrm{m}$ diam., terminal or intercalary in the aerial hyphae, solitary or in chains

Distribution. Nigeria.

Etymology. Name refers to Mada Station, a locality in Nasarawa State, Nigeria, where the species was found.

Additional isolates examined. Nigeria, Mada Station, from groundnut (Arachis hypogaea), Sept 2018, C.N. Ezekiel, CBS $146648=\mathrm{CPC} 38321=12 \mathrm{~B}(3)$, CBS $146656=$ CPC $38330=12 B(5)$; from sorghum, Jan 2019, C.N. Ezekiel, CBS $146651=$ CPC $38324=7 S(6)$. 

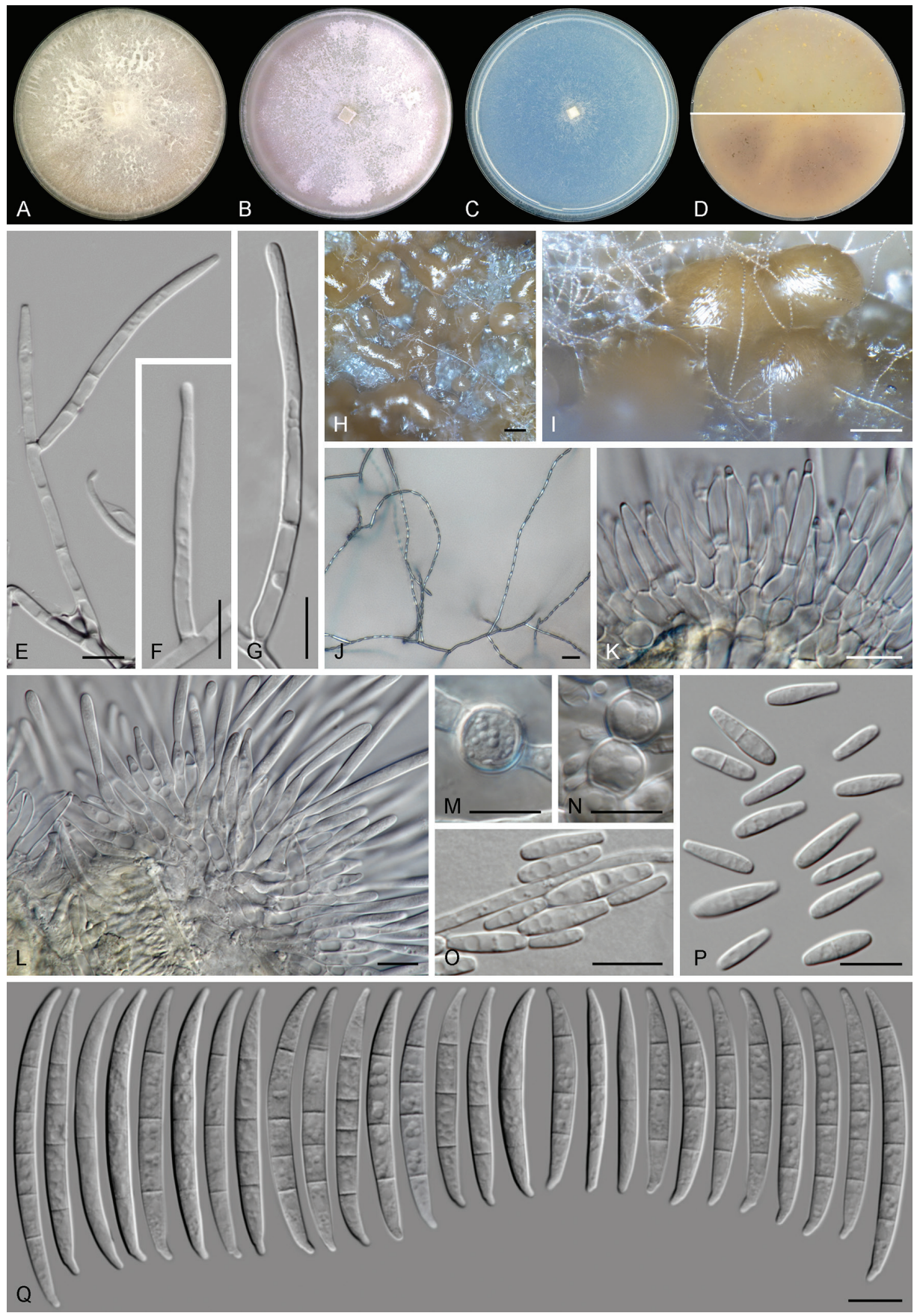

Figure 5. Fusarium madaense sp. nov. (ex-type culture CBS 146669). A-C aspect of colonies on PDA, $\mathrm{OA}$ and SNA, respectively, after $14 \mathrm{~d}$ at $24^{\circ} \mathrm{C}$ in the dark $\mathbf{D}$ colony reverse on OA (up) and PDA (down) after $14 \mathrm{~d}$ at $24^{\circ} \mathrm{C}$ in the dark $\mathbf{E}-\mathbf{G}, \mathbf{J}$ aerial conidiophores and phialides $\mathbf{H}, \mathbf{I}$ sporodochia formed on the surface of carnation leaves $\mathbf{K}, \mathbf{L}$ sporodochial conidiophores $\mathbf{M}, \mathbf{N}$ chlamydospores $\mathbf{O}, \mathbf{P}$ microconidia Q sporodochial conidia. Scale bars: $100 \mu \mathrm{m}(\mathbf{H}, \mathbf{I}) ; 20 \mu \mathrm{m}(\mathbf{J}) ; 10 \mu \mathrm{m}$ (all others). 
Notes. Although clearly recognisable based on genetic markers, Fusarium madaense is hardly distinguishable from its closer relatives, based on morphological features only. The novel species is characterised by abundant long, slender and slightly curved macroconidia, a morphology typical of the FFSC. The overall morphology of $F$. madaense is similar to that of $F$ andiyazi, $F$. thapsinum and $F$. verticillioides; all species are characterised by clavate microconidia formed in long chains from relatively long monophialides. Moreover, the four mentioned species are known to be pathogenic on sorghum (Leslie and Summerell 2006) and have been isolated here from the same geographical regions. Nevertheless, some morphological features of $F$. madaense can provide an indication of its identity. These include a pale saffron colony pigmentation on OA and PDA, not developing the intense purple colour typical of $F$ andiyazi and F. verticillioides, nor the yellow pigmentation of $F$. thapsinum; the presence of up to 3-septate clavate microconidia vs. the up to 2-septate and aseptate microconidia of $F$ andiyazi and $F$. verticillioides, respectively; and the aseptate, but also rarely napiform microconidia of F. thapsinum (Nirenberg 1976, Klittich et al. 1997, Marasas et al. 2001). In addition, $F$. madaense can be differentiated from $F$ andiyazi, its closest morphological and phylogenetic relative, by its slightly faster growth rates on PDA, somewhat wider macroconidia and the presence of true chlamydospores.

The proposal of the novel species $F$. madaense and its differentiation from $F$ andiya$z i, F$ thapsinum and $F$. verticillioides is also supported by secondary metabolite profiling of all the above-mentioned species, as found in this study. Fusarium madaense was the only beauvericin-producing species in our dataset. Nevertheless, it has been reported that $F$ verticillioides strains can produce trace levels of this toxin (Leslie et al. 2004, Leslie and Summerell 2006). The alpha-pyrones deoxyfusapyron and fusapyron were produced only by $F$. madaense and its closest relative $F$. andiyazi; by contrast, fusarin C was produced by F. madaense, $F$. thapsinum and F. verticillioides, but not by $F$. andiyazi.

\section{Conclusions}

We have shown the importance of applying robust taxonomic approaches to fungal characterisation in this study. Here, diverse fungal species, including those not previously reported from Nigerian food and soil, as well as a novel Fusarium species, F. madaense sp. nov., were identified and described. Several of these species possess mycotoxigenic, as well as plant, human and animal pathogenic, potential. We further elucidated the secondary metabolite profiles of strains within the identified fungal species. A handful of small molecule compounds were found in the cultures of the strains, including several compounds not previously reported from some strains; a few could serve as species-specific chemotaxonomic markers. Overall, we provide snapshot data on the fungal biodiversity in two north-central Nigerian states. The findings of this study are valuable to guide researchers to predict mycotoxin contamination of crops/food and possible sources of fungal infections in humans and animals, as well as to find, where unavailable and implement where available, strategies towards the control of problematic fungi and the adverse effects they may pose. 


\section{Acknowledgements}

The authors are thankful to Oluwaseun T. Ojuri, Oluwabunmi Ogunniran and Dr. Isaac M. Ogara for being helpful during sampling and isolation of fungi. CN Ezekiel deeply appreciates the International Foundation of Sciences (Sweden) for partly supporting this study through an Individual Grant (Number: I-3-E-6046-1).

\section{References}

Abdusalaam R, Atanda O, Fanelli F, Sulyok M, Cozzi G, Bavaro S, Krska R, Logrieco AF, Ezekiel CN, Salami WA (2016) Fungal isolates and metabolites in locally processed rice from five agro-ecological zones of Nigeria. Food Additives \& Contaminants: Part B 9(4): 281-289. https://doi.org/10.1080/19393210.2016.1215354

Abdus-Salaam R, Fanelli F, Atanda O, Sulyok M, Cozzi G, Bavaro S, Krska R, Logrieco AF, Ezekiel CN (2015) Fungal and bacterial metabolites associated with natural contamination of locally processed rice (Oryza sativa L.) in Nigeria. Food Additives \& Contaminants: Part A 32(6): 950-959. https://doi.org/10.1080/19440049.2015.1027880

Adebajo LO, Idowu AA, Adesanya OO (1994) Mycoflora and mycotoxins production in Nigerian corn and corn-based snacks. Mycopathologia 126(3): 183-192. https://doi. org/10.1007/BF01103774

Adejumo TO, Hettwer U, Karlovsky P (2007) Occurrence of Fusarium species and trichothecenes in Nigerian maize. International Journal of Food Microbiology 116(3): 350357. https://doi.org/10.1016/j.ijfoodmicro.2007.02.009

Adetunji MC, Atanda OO, Ezekiel CN, Sulyok M, Warth B, Beltrán E, Krska R, Obadina O, Bakare A, Chilaka CA (2014) Fungal and bacterial metabolites of stored maize (Zea mays L.) from five agro-ecological zones of Nigeria. Mycotoxin Research 30: 89-102. https:// doi.org/10.1007/s12550-014-0194-2

Afolabi CG, Bandyopadhyay R, Leslie JF, Ekpo EJ (2006) Effect of sorting on incidence and occurrence of fumonisins and Fusarium verticillioides on maize from Nigeria. Journal of Food Protection 69(8): 2019-2023. https://doi.org/10.4315/0362-028X-69.8.2019

Akinfala TO, Houbraken J, Sulyok M, Adedeji AR, Odebode AC, Krska R, Ezekiel CN (2020) Moulds and their secondary metabolites associated with the fermentation and storage of two cocoa bean hybrids in Nigeria. International Journal of Food Microbiology 316: 108490. https://doi.org/10.1016/j.ijfoodmicro.2019.108490

Amusa NA, Okechukwu R, Akinfenwa B (2007) Reactions of cowpea to infection by Macrophomina phaseolina isolates from leguminous plants in Nigeria. African Journal of Agricultural Research 2(3): 73-75.

Atehnkeng J, Ojiambo PS, Donner M, Ikotun T, Sikora RA, Cotty PJ, Bandyopadhyay R (2008) Distribution and toxigenicity of Aspergillus species isolated from maize kernels from three agro-ecological zones in Nigeria. International Journal of Food Microbiology 122: 74-84. https://doi.org/10.1016/j.ijfoodmicro.2007.11.062 
Avery SV, Singleton I, Magan N, Goldman GH (2019) The fungal threat to global food security. Fungal Biology. https://doi.org/10.1016/j.funbio.2019.03.006

Bandyopadhyay R, Atehnkeng J, Ortega-Beltran A, Akande A, Falade TDO, Cotty PJ (2019) "Ground-truthing" efficacy of biological control for aflatoxin mitigation in farmers' fields in Nigeria: From field trials to commercial usage, a 10-year study. Frontiers in Microbiology 10: 2528. https://doi.org/10.3389/fmicb.2019.02528

Bandyopadhyay R, Ortega-Beltran A, Akande A, Mutegi C, Atehnkeng J, Kaptoge L, Senghor AL, Adhikari BN, Cotty PJ (2016) Biological control of aflatoxins in Africa: current status and potential challenges in the face of climate change. World Mycotoxin Journal 9: 771-789. https://doi.org/10.3920/WMJ2016.2130

Bankole S, Schollenberger M, Drochner W (2006). Mycotoxins in food systems in sub-Saharan Africa. Mycotoxin Research 22: 163169. https://doi.org/10.1007/BF02959270

Bankole SA, Mabekoje OO, Enikuomehin OA (2003) Fusarium moniliforme and fumonisin $\mathrm{B}_{1}$ in stored maize from Ogun state, Nigeria. Tropical Science 43: 76-79. https://doi. org/10.1002/ts.93

Bautista-Rosales PU, Calderon-Santoyo M, Servín-Villegas R, Ochoa-Álvarez NA, RagazzoSánchez JA (2013) Action mechanisms of the yeast Meyerozyma caribbica for the control of the phytopathogen Colletotrichum gloeosporioides in mangoes. Biological Control 65: 293-301. https://doi.org/10.1016/j.biocontrol.2013.03.010

Baylet R, Camain R, Chabal J, Izarn R (1968) Recent contribution to the study of mycetoma in Senegal. Neotestudina rosatii. Pyrenochaeta romeroi, Aspergillus nidulans. Bulletin of the French-speaking Black African Medical Society 13: 311-313.

Chala A, Degefu T, Brurberg MB (2019) Phylogenetically diverse Fusarium species associated with sorghum (Sorghum bicolor L. Moench) and finger millet (Eleusine coracana L. Garten) grains from Ethiopia. Diversity 11(6): 93. https://doi.org/10.3390/d11060093

Chen Q, Hou LW, Duan WJ, Crous PW, Cai L (2017) Didymellaceae revisited. Studies in Mycology 87: 105-159. https://doi.org/10.1016/j.simyco.2017.06.002

Chen Q, Jiang JR, Zhang GZ, Cai L, Crous PW (2015) Resolving the Phoma enigma. Studies in Mycology 82: 137-217. https://doi.org/10.1016/j.simyco.2015.10.003

Choi J-H, Lee S, Nah J-Y, Kim H-K, Paek J-S, Lee S, Ham H, Hong SK, Yun S-H, Lee T (2018) Species composition of and fumonisin production by the Fusarium fujikuroi species complex isolated from Korean cereals. International Journal of Food Microbiology 267: 62-69. https://doi.org/10.1016/j.ijfoodmicro.2017.12.006

Crous PW, Verkley GJM, Groenewald JZ, Houbraken J (2019) Westerdijk Laboratory Manual Series 1: Fungal Biodiversity. Westerdijk Fungal Biodiversity Institute, Utrecht, The Netherlands.

De Oliveira Rocha L, Reis GM, da Silva VN, Braghini R, Teixeira MMG, Corrêa B (2011) Molecular characterization and fumonisin production by Fusarium verticillioides isolated from corn grains of different geographic origins in Brazil. International Journal of Food Microbiology 145(1): 9-21. https://doi.org/10.1016/j.ijfoodmicro.2010.11.001

de Vries RP, Frisvad JC, van de Vondervoort PJI, Burgers K, Kuijpers AFA, Samson RA, Visser J (2005) Aspergillus vadensis, a new species of the group of black Aspergilli. Antonie van Leeuwenhoek 87: 195-203. https://doi.org/10.1007/s10482-004-3194-y 
Destombes P, Mariat F, Rosati L, Segretain G (1977) Mycetoma in Somalia - results of a survey done from 1959 to 1964. Acta Tropica 34(4): 355-373.

Diedhiou PM, Bandyopadhyay R, Atehnkeng J, Ojiambo P (2011) Aspergillus colonization and aflatoxin contamination of maize and sesame kernels in two agro-ecological zones in Senegal. Journal of Phytopathology 159: 268-275. https://doi.org/10.1111/j.1439-0434.2010.01761.x

Dignani MC, Anaissie E (2004) Human fusariosis. Clinical Microbiology and Infection 10: 67-75. https://doi.org/10.1111/j.1470-9465.2004.00845.x

Donner M, Atehnkeng J, Sikora RA, Bandyopadhyay R, Cotty PJ (2009) Distribution of Aspergillus section Flavi in soils of maize fields in three agroecological zones of Nigeria. Soil Biology \& Chemistry 41: 37-44. https://doi.org/10.1016/j.soilbio.2008.09.013

El-Enshasy H, Abdel-Fattah Y, Atta A, Anwar M, Omar H, Abou El Magd S, Abou Zahra R (2008) Kinetics of cell growth and cyclosporin A production by Tolypocladium inflatum when scaling up from shake flask to bioreactor. Journal of Microbiology and Biotechnology 18(1): 128-134.

European Commission (2002) Commission Decision 2002/657 of 12 August 2002 implementing Council Directive 96/23/EC concerning the performance of analytical methods and the interpretation of results. Official Journal of the European Union L221: 8-36. https://eur-lex.europa.eu/

Ezekiel CN, Ortega-Beltran A, Oyedeji EO, Atehnkeng J, Kössler P, Tairu F, Hoeschle-Zeledon I, Karlovsky P, Cotty PJ, Bandyopadhyay R (2019) Aflatoxin in chili peppers in Nigeria: Extent of contamination and control using atoxigenic Aspergillus flavus genotypes as biocontrol agents. Toxins 11(7): 429. https://doi.org/10.3390/toxins11070429

Ezekiel CN, Oyedele OA, Kraak B, Ayeni KI, Sulyok M, Houbraken J, Krska R (2020) Fungal diversity and mycotoxins in low moisture content ready-to-eat foods in Nigeria. Frontiers in Microbiology https://doi.org/10.3389/fmicb.2020.00615

Ezekiel CN, Sulyok M, Babalola DA, Warth B, Ezekiel VC, Krska, R (2013a) Incidence and consumer awareness of toxigenic Aspergillus section Flavi and aflatoxin $\mathrm{B}_{1}$ in peanut cake from Nigeria. Food Control 30: 596-601. https://doi.org/10.1016/j.foodcont.2012.07.048

Ezekiel CN, Sulyok M, Frisvad JC, Somorin YM, Warth B, Houbraken J, Samson RA, Krska R, Odebode AC (2013b). Fungal and mycotoxin assessment of dried edible mushroom in Nigeria. International Journal of Food Microbiology 162: 231-236. https://doi. org/10.1016/j.ijfoodmicro.2013.01.025

Ezekiel CN, Sulyok M, Somorin Y, Odutayo FI, Nwabekee SU, Balogun AT, Krska R (2016) Mould and mycotoxin exposure assessment of melon and bush mango seeds, two common soup thickeners consumed in Nigeria. International Journal of Food Microbiology 237: 83-91. https://doi.org/10.1016/j.ijfoodmicro.2016.08.019

Ezekiel CN, Udom IE, Frisvad JC, Adetunji MC, Houbraken J, Fapohunda SO, Samson RA, Atanda OO, Agi-Otto MC, Onashile OA (2014) Assessment of aflatoxigenic Aspergillus and other fungi in millet and sesame from Plateau state, Nigeria. Mycology 5(1): 16-22. https://doi.org/10.1080/21501203.2014.889769

Fandohan P, Gnonlonfin B, Hell K, Marasas WFO, Wingfield MJ (2005) Natural occurrence of Fusarium and subsequent fumonisin contamination in preharvest and stored maize in Benin, West Africa. International Journal of Food Microbiology 99: 173-183. https://doi. org/10.1016/j.ijfoodmicro.2004.08.012 
Fanelli F, Schmidt-Heydt M, Haidukowski M, Susca A, Geisen R, Logrieco A, Mulè G (2012) Influence of light on growth, conidiation and fumonisin production by Fusarium verticillioides. Fungal Biology 116(2): 241-248. https://doi.org/10.1016/j.funbio.2011.11.007

Fapohunda SO, Moore GG, Ganiyu OT, Beltz SB (2012) Toxigenic Aspergillus flavus and other fungi of public health concern in food and organic matter in southwest Nigeria. Mycology 3(3): 210-219.

Fisher NL, Burguess LW, Toussoun TA, Nelson PE (1982) Carnation leaves as a substrate and for preserving cultures of Fusarium species. Phytopathology 72: 151-153. https://doi. org/10.1094/Phyto-72-151

Filtenborg O, Frisvad JC, Svendsen JA (1983) Simple screening method for moulds producing intracellular mycotoxins in pure cultures. Applied Environmental Microbiology 45: 581-585. https://doi.org/10.1128/AEM.45.2.581-585.1983

Frisvad JC, Larsen TO, de Vries R, Meijer M, Houbraken J, Cabañes FJ, Ehrlich K, Samson RA (2007) Secondary metabolite profiling, growth profiles and other tools for species recognition and important Aspergillus mycotoxins. Studies in Mycology 59: 31-37. https://doi. org/10.3114/sim.2007.59.04

Frisvad JC, Samson RA (2004) Polyphasic taxonomy of Penicillium subgenus Penicillium. A guide to identification of food and air-borne terverticillate Penicillia and their mycotoxins. Studies in Mycology 49: 1-174.

Frisvad JC, Hubka V, Ezekiel CN, Hong S-B, Novakova A, Chen AJ, Arzanlou M, Larsen TO, Sklenar F, Mahakamchanakul W, Samson RA, Houbraken J (2019) Taxonomy of Aspergillus section Flavi and their production of aflatoxins, ochratoxins and other mycotoxins. Studies in Mycology 93: 1-63. https://doi.org/10.1016/j.simyco.2018.06.001

Frisvad JC, Møller LLH, Larsen TO, Kumar R, Arnau J (2018) Safety of the fungal workhorses of industrial biotechnology: update on the mycotoxin and secondary metabolite potential of Aspergillus niger, Aspergillus oryzae, and Trichoderma reesei. Applied Microbiology and Biotechnology 102: 9481-9515. https://doi.org/10.1007/s00253-018-9354-1

Garcia RR, Min Z, Narasimhan S, Bhanot N (2015) Fusarium brain abscess: case report and literature review. Mycoses 58: 22-26. https://doi.org/10.1111/myc.12271

Groenewald JZ, Nakashima C, Nishikawa J, Shin H-D, Park J-H, Jama AN, Groenewald M, Braun U, Crous PW (2013) Species concepts in Cercospora: spotting the weeds among the roses. Studies in Mycology 75: 115-170. https://doi.org/10.3114/sim0012

Groenewald M, Groenewald JZ, Crous PW (2005) Distinct species exist within the Cercospora apii morphotype. Phytopathology 95: 951-959. https://doi.org/10.1094/PHYTO-95-0951

Houbraken J, Frisvad JC, Samson RA (2011) Taxonomy of Penicillium section Citrina. Studies in Mycology 70: 53-138. https://doi.org/10.3114/sim.2011.70.02

Houbraken J, Frisvad JC, Seifert KA, Overy DP, Tuthill DM, Valdez JG, Samson RA (2012) New penicillin-producing Penicillium species and an overview of section Chrysogena. Persoonia 29: 78-100. https://doi.org/10.3767/003158512X660571

Janevska S, Arndt B, Niehaus E-M, Burkhardt I, Rosler SM, Brock NL, Humpf H-U, Dickschat JS and Tudzynski B (2016) Gibepyrone biosynthesis in the rice pathogen Fusarium fujikuroi is facilitated by a small polyketide synthase gene cluster. Journal of Biological Chemistry 291(53): 27403-27420. https://doi.org/10.1074/jbc.M116.753053 
Katoh K, Rozewicki J, Yamada KD (2017) MAFFT online service: multiple sequence alignment, interactive sequence choice and visualization. Briefings in Bioinformatics: 1-7. https://doi.org/10.1093/bib/bbx108

Khan AN, Shair F, Malik K, Hayat Z, Khan MA, Hafeez FY and Hassan MN (2017) Molecular identification and genetic characterization of Macrophomina phaseolina strains causing pathogenicity on sunflower and chickpea. Frontiers in Microbiology 8: 1309. https://doi. org/10.3389/fmicb.2017.01309

Klittich CJR, Leslie JF, Nelson PE, Marasas WFO (1997) Fusarium thapsinum (Gibberella thapsina): A new species in section Liseola from sorghum. Mycologia 89(4): 643-652. https://doi.org/10.1080/00275514.1997.12026829

Kovac T, Borisev I, Kovac M, Loncaric A, Kenjeric FC, Djordjevic A, Strelec I, Ezekiel CN, Sulyok M, Krska R, Sarkanj B (2020) Impact of fullerol C60 (OH)24 nanoparticles on the production of emerging toxins by Aspergillus flavus. Scientific Reports 10: 725. https://doi. org/10.1038/s41598-020-57706-3

Leslie JF, Summerell BA (2006) The Fusarium laboratory manual. Blackwell Publishing, Ames. https://doi.org/10.1002/9780470278376

Leslie JF, Zeller KA, Logrieco A, Mulè G, Moretti A, Ritieni A (2004) Species diversity and toxin production by strains in the Gibberella fujikuroi species complex isolated from native prairie grasses in Kansas. Applied and Environmental Microbiology 70: 2254-2262. https://doi.org/10.1128/AEM.70.4.2254-2262.2004

Leyva-Madrigal KY, Larralde-Corona CP, Apodaca-Sánchez MA, Quiroz-Figueroa FR, Mexia-Bolaños PA, Portillo-Valenzuela S, Ordaz-Ochoa J, Maldonado-Mendoza, IE (2014) Fusarium species from the Fusarium fujikuroi species complex involved in mixed infections of maize in Northern Sinaloa, Mexico. Journal of Phytopathology 163(6): 486-497. https://doi.org/10.1111/jph.12346

Liu D, Li X, Li C, Wang B (2013) Sesterterpenes and 2H-pyran-2-ones (= $\alpha$-pyrones) from the mangrove-derived endophytic fungus Fusarium proliferatum MA-84. Helvetica Chimica Acta 96: 437-444. https://doi.org/10.1002/hlca.201200195

Makun HA, Dutton MF, Njobeh PB, Phoku JZ, Yah CS (2011) Incidence, phylogeny and mycotoxigenic potentials of fungi isolated from rice in Niger state, Nigeria. Journal of Food Safety 31: 334-349. https://doi.org/10.1111/j.1745-4565.2011.00305.x

Makun HA, Gbodi TA, Akanya OH, Salako EA, Ogbadu GH (2009) Fungi and some mycotoxins found in mouldy sorghum in Niger state, Nigeria. World Journal of Agricultural Sciences 5(1): 5-17.

Marasas WFO, Rheeder JP, Lamprecht SC, Zeller KA, Leslie JF (2001) Fusarium andiyazi sp. nov., a new species from sorghum. Mycologia 93: 1203-1210. https://doi.org/10.1080/0 0275514.2001 .12063254

Mason-Gamer R, Kellogg E (1996) Testing for phylogenetic conflict among molecular datasets in the tribe Triticeae (Graminae). Systematic Biology 45: 524-545. https://doi. org/10.1093/sysbio/45.4.524

Marley PS, Marasas WFO, Hester V (2004) Occurrence of Fusarium andiyazi associated with sorghum in Nigeria. Archives of Phytopathology and Plant Protection 37(3): 177-181. https://doi.org/10.1080/03235400410001701667 
Miller MA, Pfeiffer W, Schwartz T (2012) The CIPRES science gateway: enabling high-impact science for phylogenetics researchers with limited resources. In: Proceedings of the 1 st Conference of the Extreme Science and Engineering Discovery Environment: Bridging from the extreme to the campus and beyond, Association for Computing Machinery, Chicago, USA, 1-8. https://doi.org/10.1145/2335755.2335836

Moussa TAA, Al-Zahrani HS, Kadasa NMS, Ahmed SA, de Hoog GS, Al-Hatmi AMS (2017) Two new species of the Fusarium fujikuroi species complex isolated from the natural environment. Antonie van Leeuwenhoek 110(6): 819-832. https://doi.org/10.1007/s10482-017-0855-1

Ncube E, Flett BC, Waalwijk C, Viljoen A (2011) Fusarium spp. and levels of fumonisins in maize produced by subsistence farmers in South Africa. South African Journal of Science 107(1/2): 1-7. https://doi.org/10.4102/sajs.v107i1/2.367

Nielsen KF, Mogensen JM, Johansen M, Larsen TO, Frisvad JC (2009) Review of secondary metabolites and mycotoxins from the Aspergillus niger group. Analytical and Bioanalytical Chemistry 395: 1225-1242. https://doi.org/10.1007/s00216-009-3081-5

Nirenberg H (1976) Untersuchungen über die morphologische und biologische Differenzierung in der Fusarium-Section Liseola. Mitteilungen der Biologischen Bundesanstalt für Land- und Forstwirtschaft. 169: 1-117.

O’Donnell K, Kistler HC, Cigelnik E, Ploetz RC (1998) Multiple evolutionary origins of the fungus causing Panama disease of banana: concordant evidence from nuclear and mitochondrial gene genealogies. Proceedings of the National Academy of Sciences of the United States of America 95: 2044-2049. https://doi.org/10.1073/pnas.95.5.2044

O’Donnell K, Sutton DA, Fothergill A, McCarthy D, Rinaldi MG, Brandt ME, Zhang N, Geiser DM (2008) Molecular phylogenetic diversity, multilocus haplotype nomenclature, and in vitro antifungal resistance within the Fusarium solani species complex. Journal of Clinical Microbiology 46: 2477-2490. https://doi.org/10.1128/JCM.02371-07

O’Donnell K, Sutton DA, Rinaldi MG, Gueidan C, Crous PW, Geiser DM (2009) Novel multilocus sequence typing scheme reveals high genetic diversity of human pathogenic members of the Fusarium incarnatum - F. equiseti and F. chlamydosporum species complexes within the United States. Journal of Clinical Microbiology 47: 3851-3861. https://doi. org/10.1128/JCM.01616-09

O’Donnell K, Sutton DA, Rinaldi MG, Sarver BA, Balajee SA, Schroers HJ, Summerbell RC, Robert VA, Crous PW, Zhang N, Aoki T, Jung K, Park J, Lee YH, Kang S, Park B, Geiser DM (2010) Internet-accessible DNA sequence database for identifying fusaria from human and animal infections. Journal of Clinical Microbiology 48: 3708-3718. https://doi. org/10.1128/JCM.00989-10

O’Donnell K, Sutton DA, Wiederhold N, Robert VARG, Crous PW, Geiser DM (2016) Veterinary fusarioses within the United States. Journal of Clinical Microbiology 54: 2813-2819. https://doi.org/10.1128/JCM.01607-16

O’Donnell K, Ward TJ, Robert VARG, Crous PW, Geiser DM, Kang S (2015) DNA sequencebased identification of Fusarium: current status and future directions. Phytoparasitica 43: 583-595. https://doi.org/10.1007/s12600-015-0484-z

Oladimeji A, Balogun AS, Shittu TB (2012) Screening of cowpea genotypes for resistance of Macrophomina phaseolina infection using two methods of inoculation. Asian Journal of Plant Pathology 6: 13-18. https://doi.org/10.3923/ajppaj.2012.13.18 
Oyedele OA, Ezekiel CN, Sulyok M, Adetunji MC, Warth B, Atanda OO, Krska R (2017) Mycotoxin risk assessment for consumers of groundnut in domestic markets in Nigeria. International Journal of Food Microbiology 251: 24-32. https://doi.org/10.1016/j.ijfoodmicro.2017.03.020

Pena GA, Cavaglieri LR, Chulze SN (2018) Fusarium species and moniliformin occurrence in sorghum grains used as ingredient for animal feed in Argentina. Journal of the Science of Food and Agriculture 99(1): 47-54. https://doi.org/10.1002/jsfa.9140

Perrone G, Stea G, Epifani F, Varga J, Frisvad JC, Samson RA (2011) Aspergillus niger contains the cryptic phylogenetic species A. awamori. Fungal Biological 115: 1138-1150. https:// doi.org/10.1016/j.funbio.2011.07.008

Pitt JI, Hocking AD (2009) Fungi and Food Spoilage. Springer, London. https://doi. org/10.1007/978-0-387-92207-2

Prange A, Modrow H, Hormes J, Krämer J, Köhler P (2005) Influence of mycotoxin producing fungi (Fusarium, Aspergillus, Penicillium) on gluten proteins during suboptimal storage of wheat after harvest and competitive interactions between field and storage fungi. Journal of Agricultural and Food Chemistry 53(17): 6930-6938. https://doi.org/10.1021/jf050821t

Probst C, Bandyopadhyay R, Cotty PJ (2014) Diversity of aflatoxin-producing fungi and their impact on food safety in sub-Saharan Africa. International Journal of Food Microbiology 174: 113-122. https://doi.org/10.1016/j.ijfoodmicro.2013.12.010

Rocha LO, Barroso VM, Andrade LJ, Pereira GHA, Ferreira-Castro FL, Duarte AP, Michelotto MD, Correa B (2016) FUM gene expression profile and fumonisin production by Fusarium verticillioides inoculated in $\mathrm{Bt}$ and non-Bt maize. Frontiers in Microbiology 6: 1503. https://doi.org/10.3389/fmicb.2015.01503

Sallam LAR, El-Refai AH, Hamdy AA, El-Minofi HA, Abdel-Salam IS (2003) Role of some fermentation parameters on cyclosporine A production by a new isolate of Aspergillus terreus. Journal of General and Applied Microbiology 49: 321-328. https://doi.org/10.2323/jgam.49.321

Samson RA, Hoekstra ES, Frisvad JS, Filtenborg O (1995) Methods for the detection and isolation of food-borne fungi. In: Samson RA, Hoekstra ES, Frisvad JC, Filtenborg O (Eds) Introduction to Foodborne Fungi. Centraal Bureau voor Schimmel cultures, The Netherlands, 235-242.

Samson RA, Houbraken J, Thrane U, Frisvad JC, Andersen B (2019) Food and indoor fungi. CBS laboratory manual Series 2, second edition. Westerdijk Fungal Biodiversity Institute, Utrecht.

Samson RA, Houbraken J, Spierenburg H, Seifert KA, Peterson SW, Varga J, Frisvad JC (2011) Phylogeny and nomenclature of the genus Talaromyces and taxa accommodated in Penicillium subgenus Biverticillium. Studies in Mycology 70: 159-189. https://doi.org/10.3114/ sim.2011.70.04

Samson RA, Noonim P, Meijer M, Houbraken J, Frisvad JC, Varga J (2007) Diagnostic tools to identify black aspergilli. Studies in Mycology 59: 129-145. https://doi.org/10.3114/ sim.2007.59.13

Samson RA, Visagie CM, Houbraken J, Hong S-B, Hubka V, Klaassen CHW, Perrone G, Seifert KA, Susca A, Tanney JB, Varga J, Kocsube S, Szigeti G, Yaguchi T, Frisvad JC (2014) Phylogeny, identification and nomenclature of the genus Aspergillus. Studies in Mycology 78: 141-173. https://doi.org/10.1016/j.simyco.2014.07.004 
Sandoval-Denis M, Crous PW (2018) Removing chaos from confusion: assigning names to common human and animal pathogens in Neocosmospora. Persoonia 41: 109-129. https:// doi.org/10.3767/persoonia.2018.41.06

Sandoval-Denis M, Guarnaccia V, Polizzi G, Crous PW (2018) Symptomatic Citrus trees reveal a new pathogenic lineage in Fusarium and two new Neocosmospora species. Persoonia 40: 1-25. https://doi.org/10.3767/persoonia.2018.40.01

Sarr MP, Ndiaya M, Groenewald JZ, Crous PW (2014) Genetic diversity in Macrophomina phaseolina, the causal agent of charcoal rot. Phytopathologia Mediterranea 53: 250-268.

Sawai K, Okuno T, Tereda Y, Harada Y, Wawamura K, Sasaki H, Takao S (1981) Isolation and properties of two antifungal substances from Fusarium solani. Agricultural and Biological Chemistry 45: 1223-1228. https://doi.org/10.1271/bbb1961.45.1223

Segretain G, Destombes P (1961) Description of a new agent for maduromycosis, Neotestudina rosatii, n. gen., n. sp., isolated in Africa. CR Hebd Seances Acad Sci 253: 2577-2579.

Smedsgaard J (1997) Micro-scale extraction procedure for standardized screening of fungal metabolite production in cultures. Journal of Chromatography A 760: 264-270. https:// doi.org/10.1016/S0021-9673(96)00803-5

Stajich JE, Berbee ML, Blackwell M, Hibbert DS, James TY, Spatafora JW, Taylor JW (2009) Primer - The Fungi. Current Biology 19: R840-R845. https://doi.org/10.1016/j. cub.2009.07.004

Stamatakis A (2014) RAxML version 8: a tool for phylogenetic analysis and post-analysis of large phylogenies. Bioinformatics 30: 1312-1313. https://doi.org/10.1093/bioinformatics/btu033

Sulyok M, Stadler D, Steiner D, Krska R (2020) Validation of an LC-MS/MS-based diluteand-shoot approach for the quantification of $>500$ mycotoxins and other secondary metabolites in food crops: challenges and solutions. Analytical and Bioanalytical Chemistry https://doi.org/10.1007/s00216-020-02489-9

Swofford DL (2003) PAUP*. Phylogenetic analysis using parsimony (*and other methods), v. 4.0b10. Computer programme. Sinauer Associates, Sunderland, Massachusetts, USA.

Taniwaki MH, Pitt JI, Magan N (2018) Aspergillus species and mycotoxins: occurrence and importance in major food commodities. Current Opinion in Food Science 23: 38-43. https://doi.org/10.1016/j.cofs.2018.05.008

Uka V, Moore GG, Arroyo-Manzanares N, Nebija D, De Saeger S, Di Mavungu JD (2019) Secondary metabolite dereplication and phylogenetic analysis identify various emerging mycotoxins and reveal the high intra-species diversity in Aspergillus flavus. Frontiers in Microbiology 10: 667. https://doi.org/10.3389/fmicb.2019.00667

Varga J, Frisvad JC, Kocsubé S, Brankovics B, Tóth B, Szigeti G, Samson RA (2011) New and revisited species in Aspergillus section Nigri. Studies in Mycology 69: 1-17. https://doi. org/10.3114/sim.2011.69.01

Vesth TC, Nybo JL, Theobald S, Frisvad JC, Larsen TO, Nielsen KF, Hoof JB, Bradnl J, Salamov A, Riley R, Gladden JM, Phatale P, Nielsen MT, Lyhne EK, Kogle ME, Strasser K, McDonnell E, Barry K, Clum A, Chen C, LaButti K, Haridas S, Nolan M, Sandor L, Kuo A, Lipzen A, Hainaut M, Drula E, Tsang A, Magnuson JK, Henrissat B, Wiebenga A, Simmons BA, Makela MR, de Vries RP, Grigoriev IV, Baker SE, Andersen MR (2018) Inves- 
tigation of inter- and intraspecies variation through genome sequencing of Aspergillus section Nigri. Nature Genetics 50: 1688-1695. https://doi.org/10.1038/s41588-018-0246-1 Wang QX, Li SF, Zhao F, Dai HQ, Bao L, Ding R, Gao H, Zhang LX, Wen HA, Liu HW (2011) Chemical constituents from endophytic fungus Fusarium oxysporum. Fitoterapia 82: 777-781. https://doi.org/10.1016/j.fitote.2011.04.002

Williams SB, Baributsa D, Woloshuk C (2014) Assessing purdue improved crop storage (PICS) bags to mitigate fungal growth and aflatoxin contamination. Journal of Stored Products Research 59: 190-196. https://doi.org/10.1016/j.jspr.2014.08.003

Woudenberg JHC, Aveskamp MM, De Gruyter J, Spiers AG, Crous PW (2009) Multiple Didymella teleomorphs are linked to the Phoma clematidina morphotype. Persoonia 22: 56-62. https://doi.org/10.3767/003158509X427808

Yilmaz N, Visagie CM, Houbraken J, Frisvad JC, Samson RA (2014) Polyphasic taxonomy of the genus Talaromyces. Studies in Mycology 78: 175-341. https://doi.org/10.1016/j. simyco.2014.08.001

\section{Supplementary material I}

\section{Tables S1, S2}

Authors: Chibundu N. Ezekiel, Bart Kraak, Marcelo Sandoval-Denis, Michael Sulyok, Oluwawapelumi A. Oyedele, Kolawole I. Ayeni, Oluwadamilola M. Makinde, Oluwatosin M. Akinyemi, Rudolf Krska, Pedro W. Crous, Jos Houbraken

Data type: COL

Explanation note: Table S1. Strain details and GenBank accession numbers of molecularly identified isolates included in this study. Table S2. Strain data and accession numbers of additional strains included in phylogenetic analyses of Fusarium and related taxa.

Copyright notice: This dataset is made available under the Open Database License (http://opendatacommons.org/licenses/odbl/1.0/). The Open Database License $(\mathrm{ODbL})$ is a license agreement intended to allow users to freely share, modify, and use this Dataset while maintaining this same freedom for others, provided that the original source and author(s) are credited.

Link: https://doi.org/10.3897/mycokeys.67.52716.suppl1 